Chapter 22

\title{
rhEPO in hematopoietic stem cell transplantation
}

\author{
G. Van Straelen and Y. Beguin
}

\begin{abstract}
GV is Télévie Research Assistant and YB Research Director of the National Fund for Scientific Research (FNRS, Belgium)

Department of Medicine, Division of Hematology, University of Liège, Liège, Belgium

Center for Cellular and Molecular Therapy (Centre de Thérapie Cellulaire et Moléculaire, CTCM), University of Liège, Liège, Belgium
\end{abstract}

\section{Introduction}

Erythropoietin (Epo) is the critical regulatory factor of erythropoiesis, and recombinant human erythropoietin (rhEPO) has become a well-established treatment for chronic renal failure patients. In these subjects, endogenous serum Epo levels are very low (Erslev 1991) and the administration of rhEPO, restoring adequate levels of the hormone, permits correction of the anemia (Eschbach et al. 1987). In patients with normal kidney function, serum Epo levels increase exponentially when an anemia develops (Erslev 1991). After high-dose chemotherapy, serum Epo levels first rapidly increase to disproportionately high levels for 1-3 weeks, with peak values usually observed in the first week after the conditioning regimen (Birgegard et al. 1989; Abedi et al. 1990; Schapira et al. 1990; Beguin et al. 1991; Bosi et al. 1991a; Bosi et al. 1991b; Grace et al. 1991; Lazarus et al. 1992; Miller et al. 1992a; Beguin et al. 1993; Davies et al. 1995; Beguin et al. 1998). However, after allogeneic hematopoietic stem cell transplantation (HSCT) the Epo response to anemia then generally becomes impaired, resulting in inappropriately low levels of Epo for the degree of anemia and prolonged anemia (Ireland et al. 1990; Schapira et al. 1990; Beguin et al. 1991; Bosi et al. 1991a; Miller et al. 1992a; Beguin et al. 1993). This is specific for allogeneic transplant because serum Epo levels remain adequate throughout the posttransplant course in recipients of an autologous marrow or peripheral blood stem cell transplant (Ireland et al. 1990; Schapira et al. 1990; Beguin et al. 1991; Bosi et al. 1991b; Lazarus et al. 1992; Davies et al. 1995; Beguin et al.

This work was supported in part by grants from the National Fund for Scientific Research (FNRS, Belgium). 
1993; Beguin et al. 1998). These studies thus indicate that after auto-HSCT, the development of erythropoiesis is determined by the overall marrow proliferative activity and that erythropoietin plays only a facilitating role. On the other hand, after allo-HSCT, erythropoiesis depends on Epo production, which remains inadequate for prolonged periods of time.

This pathophysiology of endogenous erythropoietin production after HSCT suggests that the two forms of transplantation may respond differently to rhEPO. Indeed, one could expect better responses to rhEPO therapy after allogeneic HSCT, which is characterized by prolonged, severe Epo deficiency differences, compared with autologous HSCT that is associated with adequate Epo levels. Indeed, the early clinical experience with rhEPO therapy after HSCT has shown such differences. However, more recent studies have demonstrated that it is possible to optimize the timing of rhEPO administration in HSCT, resulting in higher efficacy.

We review here the clinical experience with rhEPO therapy in the setting of HSCT. After briefly describing the pathophysiology of Epo production after HSCT, we will successively address the use of rhEPO after allogeneic HSCT, its use after autologous HSCT, comparative studies after autologous and allogeneic transplantation, rhEPO therapy as preparation to HSCT, HSC mobilization with rhEPO and administration of rhEPO to HSCT donors. Finally, we will briefly comment on the specific tolerance to rhEPO in HSCT.

\section{Serum Epo levels after HSCT}

Successive phases of changes in serum Epo levels are observed after HSCT, i.e. universal peak immediately after the conditioning regimen, a progressive return to normal with erythroid recovery and a variable defect in endogenous Epo in the following months (Table 1).

Elevated serum Epo levels are observed transiently after intensive conditioning regimens without concomitant changes in hemoglobin, and this is observed in the context of autologous or allogeneic transplantation of

Table 1. Factors potentially affecting endogenous erythropoietin production after HSCT

\begin{tabular}{ll}
\hline Inhibiting factors & Stimulating factors \\
\hline Allogeneic donor & Conditioning regimen \\
Acute GVHD & Liver toxicity \\
Ciclosporin A & Anemia \\
Amphotericin B & Interstitial pneumonia \\
Cytomegalovirus infection & \\
\hline
\end{tabular}


marrow or PBSC alike (Birgegard et al. 1989; Abedi et al. 1990; Schapira et al. 1990; Beguin et al. 1991; Bosi et al. 1991a; Grace et al. 1991; Lazarus et al. 1992; Miller et al. 1992a; Beguin et al. 1993; Davies et al. 1995; Bosi et al. 1991b; Beguin et al. 1998;). This is also independent of the type of chemotherapy or the use of TBI. The peak Epo values are usually observed 0-7 days after transplant, at the time of the nadir of erythropoietic activity. As Epo exerts its action on target cells after binding to a specific Epo receptor (Youssoufian et al. 1993), severe myelosuppression following the conditioning regimen could disrupt the usual Epo degradation by Epo receptorbearing cells and provoke a surge of serum Epo concentration through prolonged Epo life span (Bowen et al. 1990; Cazzola et al. 1998). However, transplant recipients conditioned with a much milder nonmyeloablative regimen (NMSCT) still experience a surge in serum Epo levels that is quite similar to that observed after myeloablative conditioning (Baron et al. $2002 \mathrm{~b}$ ), but the reason for this observation remains unclear.

With marrow recovery after transplantation, Epo levels progressively return to an appropriate range and the duration of this correction phase inversely correlates with the speed of engraftment (Beguin et al. 1998). In addition, patients with particularly intense erythropoietic activity even exhibit somewhat decreased Epo levels during their recovery phase (Beguin et al. 1998; Baron et al. 2003b). This is consistent with increased Epo consumption by an expanding pool of erythroid precursors.

After marrow recovery, endogenous Epo remains appropriate for the degree of anemia in autologous HSCT recipients (Ireland et al. 1990; Schapira et al. 1990; Beguin et al. 1991; Bosi et al. 1991b; Lazarus et al. 1992; Beguin et al. 1993; Davies et al. 1995; Beguin et al. 1998) but rapidly becomes inadequately low in patients receiving an allogeneic transplant (Ireland et al. 1990; Schapira et al. 1990; Beguin et al. 1991; Bosi et al. 1991a; Miller et al. 1992a; Beguin et al. 1993). Therefore, the development of erythropoiesis after autologous transplantation is limited by the availability of Epo-receptor bearing erythroid precursors rather than the supply of Epo, whereas after allogeneic transplantation erythropoietic recovery is impaired because Epo levels remain inadequate for prolonged periods of time.

An obvious difference between autologous and allogeneic transplantation is the use of ciclosporin, which has been shown to affect renal function and directly inhibit Epo production (Vannucchi et al. 1991; Vannucchi et al. 1993; Vannucchi et al. 1994a). Indeed, the defect in Epo production is much more pronounced in patients receiving ciclosporin than in those undergoing T-cell depletion as prophylaxis against graft-versus-host disease (GVHD) (Abedi et al. 1990). However, there is no direct relationship between ciclosporin blood levels and the degree of impairment of Epo production (Ireland et al. 1990; Beguin et al. 1991; Miller et al. 1992a; Beguin et al. 1993). Furthermore, NMSCT recipients, who have high ciclosporin concentration, do not show the same defect in endogenous Epo levels (Baron et al. 2002b). 
A number of other factors may contribute to these differences. Epo levels inappropriately low for the degree of anemia are observed after amphotericin B administration (Lin et al. 1990), but this has not been a clear finding in HSCT recipients (Schapira et al. 1990; Miller et al. 1992a). Acute GVHD has often (Ireland et al. 1990; Beguin et al. 1991; Miller et al. 1992a; Beguin et al. 1993), but not always (Grace et al. 1991), been associated with a further depression of serum Epo levels. As the incidence and severity of acute GVHD are lower after NMSCT compared to conventional transplant (Baron et al. 2002a), this may partly explain appropriate levels of serum Epo after NMSCT (Baron et al. 2002b). On the other hand, chronic GVHD has not been found to significantly affect serum Epo levels (Beguin et al. 1991; Miller et al. 1992a; Beguin et al. 1993). CMV reactivation or clinical infection have also been found to cause a further depression of Epo production (Ireland et al. 1990; Beguin et al. 1991). Both GVHD (Ferrara et al. 2003) and CMV infection (Lacey et al. 2004) are associated with excessive production of a number of cytokines. It has been reported that IL- $1 \alpha$, IL-1 $1 \beta$, TNF- $\alpha$, IFN- $\gamma$, and TGF- $\beta$ inhibited, whereas IL-6 stimulated Epo production (Faquin et al. 1992; Chuncharunee et al. 1993; Vannucchi et al. 1994b; Nieken et al. 1995; Frede et al. 1997). Others have found inhibition of Epo production with IL-1 and TNF but not for TGF- $\beta$, IFN- $\gamma$, or IL-6 (Jelkmann et al. 1990; Fandrey et al. 1991; Jelkmann et al. 1992; Miller et al. 1992b). IL-1, TNF- $\alpha$ and IL- 6 also blocked hypoxia-induced Epo formation by the isolated rat kidney (Jelkmann et al. 1992). All these observations highlight the inhibitory properties of various cytokines on Epo production and suggest that such mechanisms may be operative after allogeneic transplantation.

\section{Treatment with rhEPO after HSCT}

\section{RhEPO after allogeneic transplantation}

In 1991, Heyll (1991) reported the first use of rhEPO in a transplant patient. A 31-yr-old man underwent allogeneic BMT for CML in chronic phase from an HLA-matched sister. There was a major ABO incompatibility between the donor and recipient. Whereas engraftment of granulocytes and platelets was adequate, anemia persisted with continuing requirements for RBC transfusions 8 months after BMT. Anemia was due to pure red cell aplasia in the presence of markedly increased endogenous Epo levels. After rhEPO was given at a dose of 4000 I.U. daily, reticulocytes began to increase and hemoglobin exceeded $10 \mathrm{~g} / \mathrm{dl}$. Two weeks later, therapy was stopped but hemoglobin levels remained around $10 \mathrm{~g} / \mathrm{dl}$ with no further need for transfusions. This report was followed by others. Paltiel et al. (1993) described the response to $\mathrm{rhEPO}$ at a dose of 50 , then $25 \mathrm{U} / \mathrm{kg} / \mathrm{d}$ for a total of 100 days in a patient with pure red cell aplasia and elevated endogenous Epo levels after ABOincompatible BMT. This resulted in prompt reticulocytosis, conversion to 
donor type blood group and correction of the anemia. Taniguchi et al. (1993) reported another patient who underwent major ABO-incompatible BMT and developed pure red cell aplasia. Despite elevated serum Epo concentration, after treating her with $9000 \mathrm{U} /$ day of rhEPO, the hemoglobin concentration increased and was maintained despite cessation of therapy 50 days later. There was a simultaneous occurrence of a drop in agglutinin titers and a possible explanation was in vivo absorption by newly produced erythroid cells. In another case reported by Ohashi et al. (1994), pure red cell aplasia after major ABO-incompatible BMT was resistant to treatment with I.V. $\gamma$-globulins, prednisolone or erythropoietin but finally responded to a combination of erythropoietin (given for 3 weeks) and methylprednisolone. Blood group converted to donor type with hemoglobin correction. Santamaria et al. (1997) reported a patient with continuing transfusion-dependent pure red cell aplasia despite conversion to donor type $\mathrm{ABO}$ blood group and titers of anti-donor isohemagglutinin being undetectable. Although endogenous serum Epo was high, treatment with a 2-wk course rhEPO resulted in rapid improvement and maintenance of normal hemoglobin thereafter. Fujisawa et al. (1996) reported 2 patients with pure red cell aplasia after major ABOincompatible BMT. One patient responded well to rhEPO with appearance of donor type $\mathrm{RBC}$ and correction of anemia, while the other patient did not respond. Ustun et al. (1999) reported a patient with myelodysplastic syndrome who developed aregenerative anemia after ABO-incompatible allogeneic PBSCT. A first course of high-dose methylprednisolone and rhEPO did not result in any improvement of anemia in the early period after allogeneic PBSCT. However, following plasma exchange a second course with higher dose of rhEPO and methylprednisolone associated with danazol was successful. Martelli et al. (1994) also reported the successful correction of pure red cell aplasia with an 8-wk course of rhEPO after an autologous peripheral blood autologous BMT with adequate endogenous Epo levels. There is also a report of two patients with osteomyelofibrosis and prolonged anemia after PBSCT that responded well after being switched from erythropoietin to darbepoietin alpha (Nguyen et al. 2003). Delayed immune hemolysis is another possible complication of major ABO-incompatible bone marrow transplant. Instead of increasing immunosuppression, Lopez et al. (1994) gave erythropoietin and observed an increase in reticulocytes sufficient to maintain hemoglobin despite persistent hemolysis. A dose of $125 \mathrm{U} / \mathrm{kg} /$ day was initially required but rhEPO could finally be discontinued with no further hemolytic episode.

However, the most frequent cause of prolonged anemia after allogeneic BMT is a marked impairment of Epo production in response to anemia. Locatelli et al. (1992) reported 2 children with aplastic anemia undergoing allogeneic BMT with partially matched family donors who, after initial erythropoietic recovery, became severely anemic in the presence of inappropriately low serum Epo levels. Both were treated with rhEPO at an initial dosage of $50 \mathrm{U} / \mathrm{kg} 3$ times weekly and experienced a prompt reticulocyte and 
hemoglobin response. A hemoglobin level around $12 \mathrm{~g} / \mathrm{dl}$ was maintained with a single weekly SC administration of rhEPO. Fujimori et al. (1998) treated 9 patients with late-onset anemia caused by GVHD, CMV infection or impaired Epo secretion more than 50 days after allogeneic BMT. Very short courses (median 3 weeks) of rhEPO were given in most instances and $6 / 9$ patients responded well, including 2 achieving $\mathrm{Hb}$ levels $\geq 13 \mathrm{~g} / \mathrm{dL}$. The 3 patients with GVHD did not respond.

Miller et al. (1994) conducted an open trial of rhEPO in 18 allo-BMT recipients and compared them to 50 historical controls. RhEPO was given IV at the dose of 500-1,000 U/kg/wk in 5 doses between day 1 and 28, followed by $450-900 \mathrm{U} / \mathrm{kg} / \mathrm{wk}$ in 3 doses between days 29 and 70 . Although the median time to a corrected reticulocyte count $>0132 \%$ was significantly reduced from 31 to 19 days, there was no effect on the number of RBC transfusions given between days 5 and 82 (16 vs 19). Interestingly, median time to 1,000 leukocytes was less in the rhEPO patients ( 14 vs $17, \mathrm{p}=0.03)$ but the median time to 500 granulocytes was not different.

Vannucchi et al. (1992) treated 8 allogeneic BMT patients with $1,050 \mathrm{U} / \mathrm{kg} / \mathrm{wk}$ IV rhEPO given in 3 daily IV injections from day 1 to day 30 . There was no difference in neutrophil or platelet engraftment nor in the number of platelet transfusions. Erythroid engraftment was faster in patients receiving rhEPO, as illustrated by a shorter time to high fluorescent reticulocyte count $\geq 10,000 / \mu$ l or to an Hct $\geq 35 \%$, as well as by higher total and high fluorescent reticulocyte counts at day 21 . As a consequence, the number of RBC transfusions was sharply reduced from 11 to 4 units per patient.

Link et al. (1993) administered 1,050 U/kg/wk of rhEPO by continuous IV infusion to 19 allo-BMT recipients until the Hct exceeded $35 \%$ for one week without transfusion. Erythrocyte engraftment was much faster and this translated into higher reticulocyte counts at day $22(\mathrm{p}=0.042)$ or day 29 $(\mathrm{p}=0.065)$, as well as into a shorter time to transfusion independence (17 vs 24 days, $\mathrm{p}=0.015)$. As compared to the 43 historical controls, the number of $\mathrm{RBC}$ transfusions was reduced from $10 \pm 7 \mathrm{U}$ to $7 \pm 4 \mathrm{U}$ between days 0 and 30 and this was at the limit of statistical significance. There were no data available for total RBC requirements.

Locatelli et al. (1993) carried out a pilot study of rhEPO to accelerate erythroid engraftment in 15 children receiving an allogeneic transplant. Erythropoietin was given daily IV at the dose of $525 \mathrm{U} / \mathrm{kg} / \mathrm{wk}$ from day 1 to day 30 . As compared to 16 historical controls, median times to 500 neutrophils or 50,000 platelets were not affected. However, the number of platelet transfusions administered between days 0 and 30, as well as the total number of platelet transfusions, were significantly less in the rhEPO patients. Engraftment of the erythroid lineage was consistently accelerated and this translated into day 30 reticulocyte counts, as well as day 15 or day 30 sTfR levels that were about twice as high as in controls. This accelerated erythroid recovery and resulted into a significant reduction in the number of RBC transfusions administered. 
Vannucchi et al. (1997) conducted a small randomized placebo-controlled trial in which rhEPO or placebo was administered at enormous doses $(3,500$ $\mathrm{U} / \mathrm{kg} / \mathrm{wk}$ ) by continuous infusion for 30 days to 20 patients undergoing an allogeneic BMT. Treatment with erythropoietin produced signs of accelerated erythropoiesis with higher reticulocyte and sTfR values, resulting in a two-fold reduction in $\mathrm{RBC}$ transfusion requirements in the first 30 days posttransplant. No significant effect was noted on granulopoiesis, platelet recovery or the number of platelet transfusions.

Steegmann et al. (1992) randomized 28 allogeneic BMT patients between rhEPO given daily IV for a total dose of $1,050 \mathrm{U} / \mathrm{kg} / \mathrm{wk}$ between days 0 and 30 or no treatment. Among 24 evaluable patients, 13 received rhEPO and 11 no treatment. Neutrophil engraftment was not affected by therapy but the median time to 25,000 platelets was significantly reduced by about one third and the median number of platelet transfusions transfused in the first 30 days was greatly diminished. Erythroid engraftment, as measured by median time to $0.5 \%$ or $2 \%$ reticulocytes, was considerably accelerated, with the consequence that the number of RBC transfusions was reduced by two-thirds.

Biggs et al. (1995) conducted a prospective double-blind placebocontrolled trial in 91 recipients of an allogeneic transplant (Table 2). Erythropoietin was given IV 3 times a week for a total of $900 \mathrm{U} / \mathrm{kg} / \mathrm{wk}$ from day 1 to day 42. Neutrophil and platelet engraftments were the same between 48 rhEPO patients and 43 placebo patients. After day 14, reticulocyte counts and hemoglobin levels were significantly higher in the rhEPO group. Despite this enhancement of erythroid activity, RBC transfusion needs within the first 6 weeks after transplantation were not improved ( $6 \pm 5$ vs $7 \pm 5$ units) and there was also no effect on platelet transfusion requirements during the same time period (11 \pm 9 vs $11 \pm 7$ transfusions). In multivariate analysis rhEPO use was associated with only an $18 \%$ reduction in $\mathrm{RBC}$ transfusion requirements.

Table 2. Treatment with rhEPO (300 U/kg tiw IV days 0-42) after allo-BMT (Biggs et al. 1995)

\begin{tabular}{llll}
\hline & $\begin{array}{l}\text { rhEPO } \\
(\mathrm{N}=48)\end{array}$ & $\begin{array}{l}\text { Placebo } \\
(\mathrm{N}=43)\end{array}$ & P value \\
\hline Days to neutrophils $>500 / \mu \mathrm{l}$ & $20 \pm 4$ & $20 \pm 5$ & $\mathrm{NS}$ \\
Days to neutrophils $>1,000 / \mu \mathrm{l}$ & $25 \pm 7$ & $23 \pm 5$ & $\mathrm{NS}$ \\
Days to platelets $>50,000 / \mu \mathrm{l}$ & $29 \pm 6$ & $26 \pm 5$ & $\mathrm{NS}$ \\
Platelet transfusions (days 0-42) & $11 \pm 9$ & $11 \pm 7$ & $\mathrm{NS}$ \\
Hb $(\mathrm{g} / \mathrm{dl})$ at day 28 & 10.1 & 11.3 & 0.003 \\
Reticulocytes $\left(\times 10^{3} / \mu \mathrm{l}\right)$ at day 19 & 31.8 & 9.6 & 0.008 \\
RBC transfusions (days 0-42) & $6 \pm 5(*)$ & $7 \pm 5$ & $\mathrm{NS}$ \\
\hline
\end{tabular}

* Multivariate analysis: $82 \%$ of control group $(\mathrm{P}=0.022)$. 
Table 3. Treatment with rhEPO (200 U/kg/d IV days 1-28, $200 \mathrm{U} / \mathrm{kg}$ biw IV days 29-56) after allo-BMT (Klaesson et al. 1994b; Klaesson et al. 1994a)

\begin{tabular}{|c|c|c|c|}
\hline & $\begin{array}{l}\mathrm{rhEPO} \\
(\mathrm{N}=22)\end{array}$ & $\begin{array}{l}\text { Placebo } \\
(\mathrm{N}=23)\end{array}$ & $\mathrm{P}$ value \\
\hline Days to $\mathrm{WBC}>200 / \mu \mathrm{l}$ & 16 & 17 & NS \\
\hline Days to neutrophils $>500 / \mu 1$ & 20 & 20 & NS \\
\hline Platelet transfusions (days 0-60) & $16 \pm 12$ & $17 \pm 15$ & NS \\
\hline Day of last platelet transfusion & $24 \pm 13$ & $29 \pm 17$ & NS \\
\hline Reticulocytes (\%) at month 1 & $1.0 \pm 0.9$ & $1.1 \pm 2.6$ & NS \\
\hline Reticulocytes (\%) at month 2 & $2.7 \pm 1.3$ & $2.9 \pm 2.7$ & NS \\
\hline Days to reticulocytes $>2 \%$ & $15 \pm 5$ & $17 \pm 5$ & NS \\
\hline Hct $(\%)$ at month 1 & $26 \pm 3$ & $24 \pm 2$ & 0.03 \\
\hline Hct (\%) at month 2 & $30 \pm 4$ & $26 \pm 3$ & 0.01 \\
\hline RBC transfusions (days 0-60) & $5 \pm 5$ & $10 \pm 9$ & 0.04 \\
\hline Day of last RBC transfusions & $17 \pm 14$ & $30 \pm 22$ & 0.03 \\
\hline Days to $\mathrm{Hb}>7 \mathrm{~g} / \mathrm{dl}$ without transfusion & 14 & 24 & 0.03 \\
\hline Number of patients with $\mathrm{Hb}>12 \mathrm{~g} / \mathrm{dl}$ & 7 & 0 & 0.004 \\
\hline
\end{tabular}

In the study reported by Klaesson et al. (1994a,b), patients undergoing allogeneic BMT were randomized to IV placebo $(\mathrm{n}=25)$ or rhEPO $(\mathrm{n}=25)$ (Table 3). Erythropoietin was first given daily for a total dose of $1,400 \mathrm{U} / \mathrm{kg} / \mathrm{wk}$ for 4 weeks and then twice a week for a total dose of $400 \mathrm{U} / \mathrm{kg} / \mathrm{wk}$ for an additional 4 weeks. Neutrophil and platelet engraftments were not different in the 2 groups and there was no difference in number of platelet transfusions administered. Although there was no difference in reticulocyte counts after 4 or 8 weeks or for the median time to $2 \%$ reticulocytes, hematocrit was significantly higher in the rhEPO group after 4 weeks, as well as after 8 weeks. Consequently, transfusion independence was achieved sooner when rhEPO was given and the number of RBC transfusions received within 60 days was diminished by half. Seven of the treated patients compared with none of the controls reached a hemoglobin $\geq 12 \mathrm{~g} / \mathrm{dl}$ during the study period.

There is only one pilot trial of combined administration of rhEPO and G-CSF in patients undergoing allogeneic bone marrow transplantation (Locatelli et al. 1994b). Thirteen children in group 1 received $75 \mathrm{U} / \mathrm{kg} /$ day rhEPO given IV from day 1 to day 30 plus G-CSF $5 \mu \mathrm{g} / \mathrm{kg} /$ day given IV from day 5 to a WBC count $\geq 5,000 / \mu \mathrm{l}$. Group 2 consisted of 15 children receiving rhEPO alone and group 3 of 16 historical controls receiving no rhEPO. Patients receiving G-CSF had a faster neutrophil engraftment than the two other groups. The median time to 30,000 or 50,000 platelets was significantly shorter in patients receiving rhEPO with or without G-CSF as compared to historical controls and the number of platelet transfusions was reduced by more than half. The two groups of patients receiving rhEPO showed an accel- 
erated erythropoietic recovery as assessed by reticulocyte counts at day 30 or sTfR levels at day 15 or day 30 . Although their rate of erythroid engraftment appeared to be similar, there was an apparent synergistic effect of rhEPO and G-CSF on the number of red cell transfusions, which were two times less in patients receiving combined treatment as compared to those receiving rhEPO alone, the latter having also less transfusion needs than historical controls.

These trials of rhEPO therapy after allogeneic HSCT have not taken the pathophysiology of erythropoiesis into account. All studies to date have administered very high doses (usually $>1,000 \mathrm{U} / \mathrm{kg} / \mathrm{wk}$ ) of rhEPO starting on day 1 and continuing for 1-2 months or until erythroid engraftment, and thus the cost was prohibitive. Pilot trials showed accelerated erythropoiesis with increased reticulocyte, sTfR and/or hematocrit values, as well as a reduction in RBC transfusions compared to historical controls (Steegmann et al. 1992; Link et al. 1993; Locatelli et al. 1993; Locatelli et al. 1994a,b; Vannucchi et al. 1997). Some even reported an impact on platelet engraftment and/or platelet transfusions(Steegmann et al. 1992; Locatelli et al. 1994a,b). However, larger placebo-controlled studies with rhEPO doses 900-1,400 U/kg/wk confirmed the potential for accelerating red cell but not platelet recovery (Klaesson et al. 1994a; Link et al. 1994). A reduction in RBC transfusions was observed in some studies, but only between day 20 and 40 (not overall), and particularly in patients with severe acute GVHD, in the largest trial. Therefore, soaking patients with huge doses of rhEPO at a time when the erythroid marrow has not developed enough erythroid precursors to respond and when many intercurrent complications such as organ toxicity, infection, acute GVHD, and bleeding may blunt response may not be the best way to use rhEPO after an allogeneic transplant.

Therefore, we looked for a more physiological approach. Baron (Baron et al. 2002c) enrolled 34 recipients of an allogeneic HSCT in 3 consecutive trials to determine the optimal utilization of rhEPO therapy in this setting. RhEPO was started on day 1 in 7 patients at a dose of 1,400 IU/kg/week in the first trial, between day 56 and 1,440 in 13 other patients at a dose of $500 \mathrm{U} / \mathrm{kg} /$ week in a second trial, and finally on day 35 in another group of 14 patients at a dose of $500 \mathrm{U} / \mathrm{kg} /$ week in a third trial. In the first trial (only PBSCT recipients), compared to a historical group of 10 patients, erythroid recovery (median time to $1 \%$ reticulocytes: 12 vs 27 days) and $\mathrm{RBC}$ transfusion independence ( 21 vs 40 days) were significantly faster in the study group but the transfusion requirements were not reduced. In the second trial, responses to rhEPO were high with transfusions significantly reduced already in the first month of rhEPO therapy, transfusion independence achieved in one week in 12 of 13 patients $(92 \%)$ and $2 \mathrm{~g} / \mathrm{dL} \mathrm{Hb}$ increments achieved after a median of 6 weeks. In the third trial that involved only PBSCT recipients, transfusion independence was achieved after one week in 13 of 14 patients (92\%), $2 \mathrm{~g} / \mathrm{dL} \mathrm{Hb}$ increment after 3 wks and normal $\mathrm{Hb}$ values after 8 wks. 
Median number of transfusions per month decreased from 3 at baseline to 0 in months 1, 2 and 3 of rhEPO therapy. The anemia after allogeneic HSCT is thus exquisitely sensitive to rhEPO. The benefit is minimal when it is given early post-transplant, as used in all trials to date. However, the rate of major response is $>90 \%$ when rhEPO is started after day 35 .

These results were then confirmed in another study published by Baron et al. (Baron et al. 2003a) who enrolled 13 recipients of an allogeneic PBSCT in a trial of rhEPO therapy given at a once-weekly dose of $500 \mathrm{U} / \mathrm{kg} /$ week starting on day 30 post-transplant and compared them to an untreated group control of 10 patients. This again demonstrated that rhEPO therapy is very effective when started one month after transplantation, with an overall probability of achieving an $\mathrm{Hb}$ level $\geq 13 \mathrm{~g} / \mathrm{dL}$ of $91 \%$ versus $14 \%$ in controls. After 2 weeks of treatment, transfusion independence was achieved in 12/13 (92\%) patients vs $5 / 10(50 \%)$ patients in the control group $(\mathrm{p}=0.05)$. RBC transfusions were no longer required between day 50 and 150 post-transplant in $11 / 13$ patients in the rhEPO group vs $3 / 10$ patients in the control group ( $\mathrm{p}=$ 0.0131). The rhEPO group was then compared to a historical group of patients receiving rhEPO at the same total dose and starting also on day 30, but administered in three injections. There was no significant difference between the two groups in terms of erythropoietic activity or RBC transfusion requirements (Fig. 1).

Our data set the stage for a more rational use of rhEPO after allogeneic HSCT and should renew interest in erythropoietin therapy after the relative disappointment with previous trials that targeted initial erythroid recovery rather than the more physiologically appropriate period that follows engraftment.

\section{RhEPO after autologous transplantation}

The results of treatment with rhEPO after autologous BMT have remained much more disappointing until recently. In the study published by Ayash et al. (1994), 10 patients with solid tumors undergoing autologous BMT received iron supplementation along with daily IV injections of rhEPO for a total dose of 1,400 U/kg/wk for 4 weeks. As compared to 37 historical controls, median times to 500 neutrophils or to 20,000 platelets were not shortened, but median time to an Hct $\geq 30 \%$ was reduced by half ( 24 vs about 57 days, $\mathrm{p}=0.001$ ). Eight out of $10 \mathrm{rhEPO}$ vs 20 out of 37 historical controls achieved an Hct of $30 \%$ within 32 days but this difference did not reach statistical significance. The number of RBC transfusions was the same ( 9 vs 9 units) in the two groups.

In the study published by Filip et al. (1999), 11 patients with breast cancer undergoing 5 cycles of chemotherapy supported by PBPC infusions were given G-CSF and rhEPO. Compared with 12 historical controls receiving the same treatment plan but without growth factors, the duration of neutropenia 

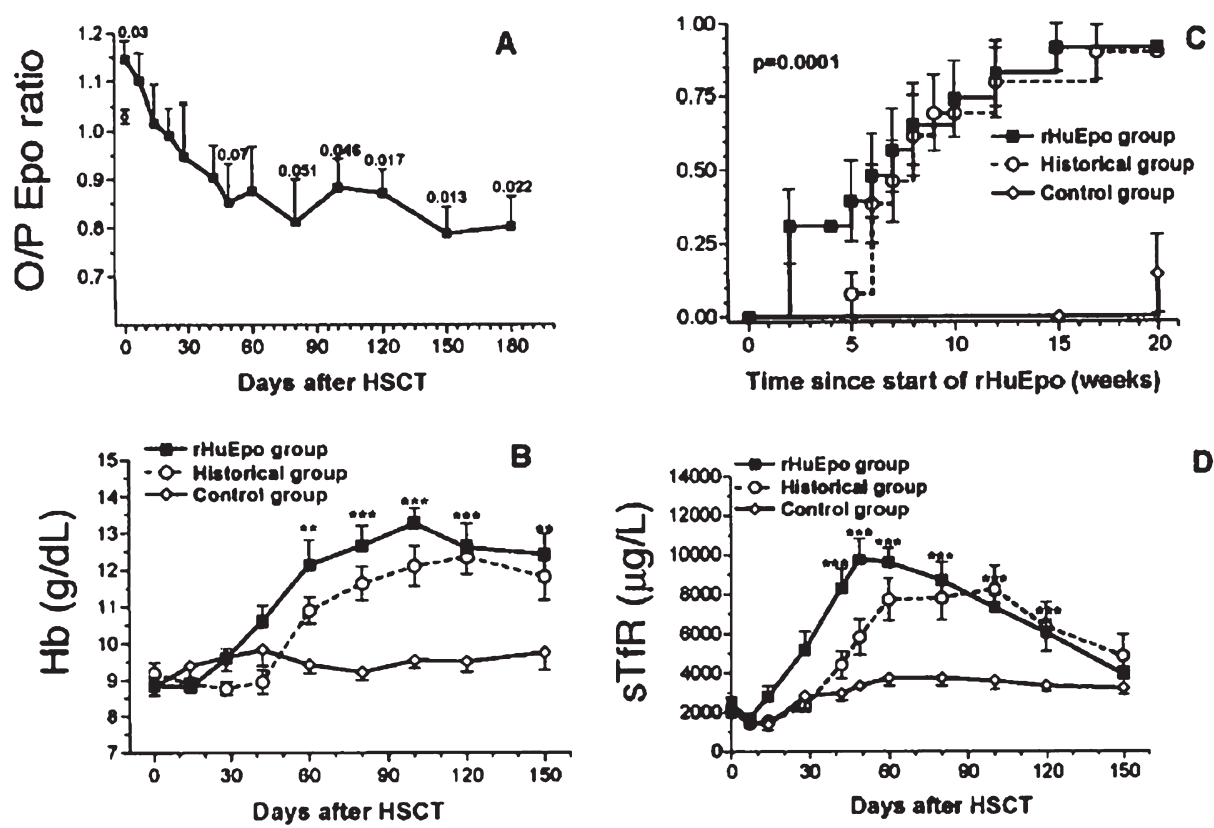

Fig. 1. (A) Endogenous erythropoietin production after allogenic peripheral blood hematopoietic stem cell transplantation (HSCT), as assessed by observed to predicted $(\mathrm{O} / \mathrm{P})$ erythropoietin ratios $(\mathrm{Mean}+\mathrm{SEM})$. The mean value in normal donors is also shown (open circle). (B) Kaplan-Meier plots of time to $\mathrm{Hb}>13 \mathrm{~g} / \mathrm{dL}$. (C-D) $\mathrm{Hb}(\mathbf{C})$ and serum transferrin receptor (sTfR) (D) from day of transplantation in rhEPO group (rhEPO once weekly), historical group (rhEPO at the same dose thrice weekly), and control group (no rhEPO). $p$ values are given for comparisons of the rhEPO group with the control group: $(*)<0.05 ;(* *)<0.01 ;(* * *)<0.001$. From Baron et al. (2003a) with permission

was shorter, the severity of thrombocytopenia was lower, and the number of platelet and red cell transfusions was smaller. However, the need for PBPC support for an epirubicin-cyclophosphamide regimen is questionable and in this context, rhEPO treatment is more analogous to the setting of the anemia of cancer and chemotherapy than to that of transplantation.

Miller et al. (1994) conducted a randomized, double-blind trial of rhEPO vs placebo in 50 patients undergoing auto-BMT with purged marrow for acute myelogenous leukemia or non-Hodgkin's lymphoma. Twenty-six patients received rhEPO IV daily for a total dose of $1,400 \mathrm{U} / \mathrm{kg} / \mathrm{wk}$ for 4 weeks followed by 3 injections per week for a total dose of $600 \mathrm{U} / \mathrm{kg} / \mathrm{wk}$ from day 29 to day 50. Median times to 500 neutrophils or 50,000 platelets were the same in the two groups and, consequently, there was no difference in the number of platelet transfusions required in the first 50 days after the transplant. Although there was no difference in the median time to reach a 
corrected reticulocyte count $\geq 2 \%$, the $\mathrm{Hb}$ level at day 50 was higher in the rhEPO group ( $10.5 \mathrm{vs} 9.5 \mathrm{~g} / \mathrm{dl}, \mathrm{p}=0.02)$, but this did not translate into reduced $\mathrm{RBC}$ requirements (13 vs $15 \mathrm{U})$.

Because of the poor results obtained with rhEPO alone in auto-BMT recipients, several trials were conducted using a combination of rhEPO and a myeloid growth factor, either G-CSF or GM-CSF. Pene et al. (1993) gave rhEPO at the dose of $150 \mathrm{U} / \mathrm{kg} /$ day IV and GM-CSF at the dose of $10 \mu \mathrm{g} / \mathrm{kg} / \mathrm{d}$ IV to 18 autologous BMT patients. RhEPO was given until $\mathrm{Hb}$ reached $12 \mathrm{~g} / \mathrm{dl}$ and GM-CSF until the neutrophils reached 500/ $\mu$ l. As compared to 6 concomitant controls receiving GM-CSF and placebo and 65 historical controls receiving GM-CSF alone, there was no difference for the median time to 500 neutrophils ( 13 vs 18 vs 19 days), median time to 50,000 platelets ( 31 vs 28 vs 26 days) or the median time to an $\mathrm{Hb} \geq 12 \mathrm{~g} / \mathrm{dl}$ ( $12 \mathrm{vs} 12 \mathrm{vs}$ ? days). As a consequence, there was no difference between rhEPO and placebo for the number of platelet (26 vs 28 transfusions) or RBC (10 vs 12 units) transfusions.

Pedrazzini (1993) compared 6 patients receiving a combination of IV rhEPO (300 U/kg/day) and GM-CSF $\left(250 \mu \mathrm{g} / \mathrm{m}^{2} /\right.$ day), given from day 10 to the day on which a neutrophil count of $500 / \mu 1$ was achieved, with 7 control patients. There was no difference for the median times to 500 neutrophils (39 vs 31 days), to 20,000 platelets (45 vs 46 days) or to $10 \mathrm{~g} / \mathrm{dl}$ of hemoglobin (61 vs 75 days). Consequently, the number of platelet transfusions was not different nor was the number of RBC transfusions between day 0 and 35 (10 \pm 3 vs $10 \pm 7)$ or after day $35(5 \pm 7$ vs $8 \pm 12)$.

Pierelli et al. (1996) gave rhEPO (150 U/kg SC every 48 hours, days 1-11) and $\mathrm{G}-\mathrm{CSF}(5 \mu \mathrm{g} / \mathrm{kg} / \mathrm{d} \mathrm{SC}$, days 1-12) to 15 patients with breast or ovarian carcinoma undergoing intensive chemotherapy followed by peripheral blood stem cell support. Compared to 8 historical controls, neutrophil and platelet engraftments were accelerated and the number of platelet transfusions was reduced, but there was no effect on erythroid recovery. The same group (Benedetti et al. 1997) later extended their observations with the same protocol, adding 2 further controls and 15 patients receiving the same schedule of rhEPO but with GM-CSF $(5 \mu \mathrm{g} / \mathrm{kg} / \mathrm{d}$, days 1-12). The use of either growth factor combination reduced the duration of neutropenia similarly. With 10 instead of 8 controls, the effect on platelet recovery and platelet transfusions was no longer significant. There was no impact of either growth factor combination on $\mathrm{RBC}$ transfusion requirements.

Olivieri et al. (2004) conducted a trial combining rhEPO and G-CSF in 32 multiple myeloma and lymphoma patients undergoing 39 cycles of autologous HSCT. Starting on day 1, G-CSF was administrated until neutrophil engraftment, while rhEPO was given at the dose of 10,000 U/d for 3 weeks starting on day 1. Compared to a historical control group, neutrophil and platelet reconstitution was significantly faster in patients receiving the combination of G-CSF and rhEPO, but only by a few days to 500 neutrophils or 20,000 platelets $/ \mu \mathrm{L}$. The median duration of neutropenia was also significantly shorter by 2 days, as were the numbers of days with fever or on anti- 
biotics. Finally, platelet (1 vs 2 ) and RBC (0 vs 2$)$ transfusion requirements were almost abolished in the treated patients. As the duration of hospitalization was decreased to a median of 9.5 days (4-27) compared with 22 (15-43) in the control group, the mean estimated cost of the transplant procedure with Epo + G-CSF was 18,394 Euros in patients treated with Epo+G-CSF, compared to 23,988 Euros in the control group. However, the major problem of this retrospective analysis is that G-CSF was only started on day 5 in the control group, compared to day 1 in the G-CSF group. This could delay neutrophil engraftment, facilitate infections and hence have deleterious effects on transfusion needs and duration of hospitalization.

Chao et al. (1994) randomized 35 patients with Hodgkin's or nonHodgkin's lymphoma to receive rhEPO $(600 \mathrm{U} / \mathrm{kg} / \mathrm{wk}$, IV from day 1 to day 30 ) or placebo in addition to G-CSF given at the dose of $10 \mu \mathrm{g} / \mathrm{kg} / \mathrm{day}$ IV

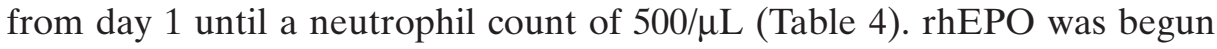
3 weeks before administration of high-dose therapy but was held during the week of the preparatory regimen. There was no difference between the 18 rhEPO patients and the 17 placebo patients for the times to 500 neutrophils (12 vs 10 days) or 20,000 platelets ( 22 vs 20 days), number of platelet (10 vs 5 transfusions) or RBC ( 8 vs 6 units) transfusions between day 0 and day 30 . Vannucchi et al. (1996) conducted an open randomized pilot study using the combination of rhEPO (150 U/kg/day IV from day 1 to day 21) ANC and G-CSF $(5 \mu \mathrm{g} / \mathrm{kg} /$ day SC from day 1 to ANC recovery) in 30 patients suffering from malignant disorders of the lymphoid lineage and undergoing autoBMT. Ten patient each received G-CSF and rhEPO, G-CSF alone or no growth factor. Neutrophil engraftment was faster in patients receiving GCSF. No effect on platelet engraftment or platelet transfusion requirements was observed. Median time to $30 \times 10^{9} / \mathrm{L}$ reticulocytes was significantly reduced with rhEPO but hematocrit recovery to $\geq 30 \%$ was not faster. In addition, RBC transfusion needs were not reduced by rhEPO, although both groups receiving G-CSF had one-third less transfusions than the control group.

Perillo et al. (2002) also examined the impact of the addition of low-dose Il-2 to the combination of G-CSF + EPO, all given from day 1 through to day

Table 4. Combined treatment with rhEPO (600 U/kg tiw IV days 1-30) and G-CSF after auto-BMT (Chao et al. 1994)

\begin{tabular}{llll}
\hline & $\begin{array}{l}\text { G-CSF + rhEPO } \\
(\mathrm{N}=18)\end{array}$ & $\begin{array}{l}\text { G-CSF + placebo } \\
(\mathrm{N}=17)\end{array}$ & P Value \\
\hline Days to neutrophils $>500 / \mu \mathrm{l}$ & 12 & 10 & $\mathrm{NS}$ \\
Days to platelets $>20,000 / \mu \mathrm{l}$ & 22 & 20 & $\mathrm{NS}$ \\
Platelet transfusions (days 0-30) & 10 & 5 & $\mathrm{NS}$ \\
RBC transfusions (days 0-30) & 8 & 6 & $\mathrm{NS}$ \\
\hline
\end{tabular}

Median values. 
12 post-transplant. To this end, two consecutive series of breast or ovarian cancer patients undergoing autologous PBSCT were compared, the first 17 patients receiving G-CSF plus rhEPO (150 U/kg/dose every 48 hours) and the last 15 the same combination plus IL-2. Hematopoietic and post-transplant clinical courses were comparable. In particular, transfusion requirements and duration of hospitalization were similar. The addition of IL-2 to the combination of G-CSF + EPO produced various effects on immune reconstitution but had no specific impact on erythropoiesis.

All these trials of rhEPO therapy after autologous HSCT have not taken the pathophysiology of erythropoiesis into account. All studies have administered very high doses of rhEPO starting on day 1 and continuing for 1-2 months or until erythroid engraftment and have shown no advantage to rhEPO therapy. Therefore, soaking patients with huge doses of rhEPO at a time when the erythroid marrow has not developed enough erythroid precursors to respond and when endogenous Epo production is appropriate or even excessive for the degree of anemia may not be the best way to use rhEPO after transplantation.

A more physiological alternative could be the administration of rhEPO starting one month after transplantation. Baron et al. (2003b) enrolled 41 consecutive patients with lymphoma or myeloma in a trial of rhEPO therapy given at a dose of $500 \mathrm{U} / \mathrm{kg} / \mathrm{wk}$ starting on day 30 post-transplant. Compared with a historical control group of 45 consecutive patients, Hb levels were significantly higher in the rhEPO group from day 42 through day 150 post-transplant. Eight of 45 patients in the control group versus 0 of 41 patients in the rhEPO group required RBC transfusions after day $30(p=0.0059)$ (Figs. 2 and 3 ).

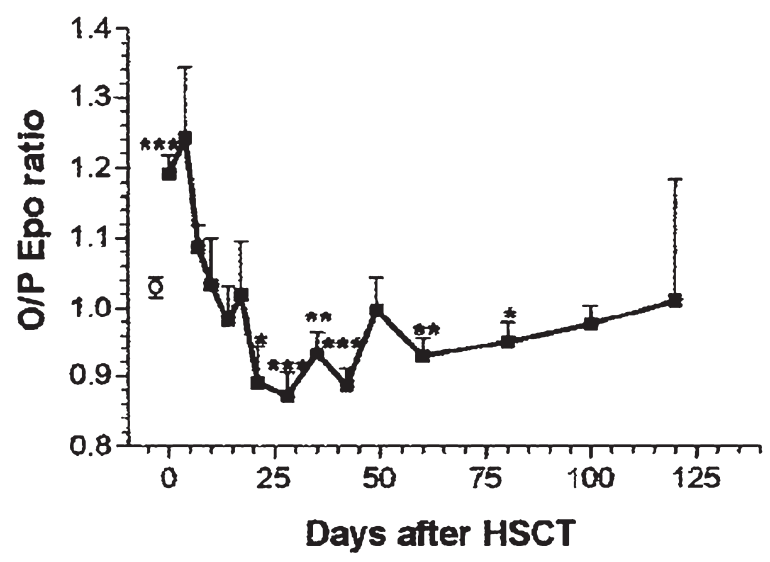

Fig. 2. Endogenous serum Epo levels, as assessed by observed to predicted $(\mathrm{O} / \mathrm{P})$ Epo ratios (mean $\pm \mathrm{SE}$ ) in 45 patients after autologous peripheral blood hematopoietic stem cell transplantation (HSCT). Mean \pm SE values of 31 normal donors are also shown (open circle) (From Baron et al. (2003b) with permission) 


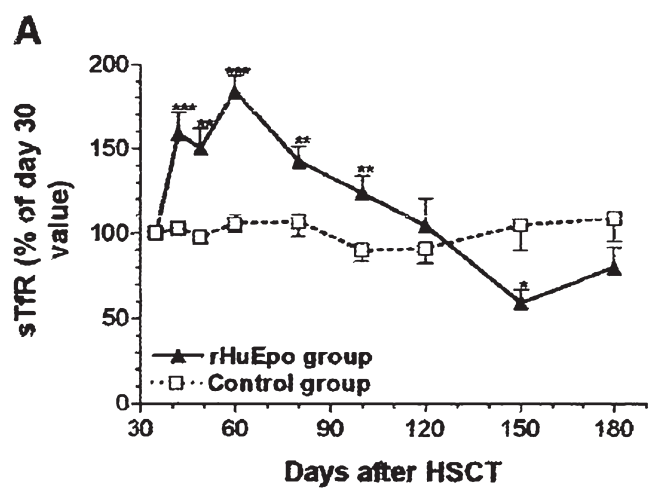

\section{B}
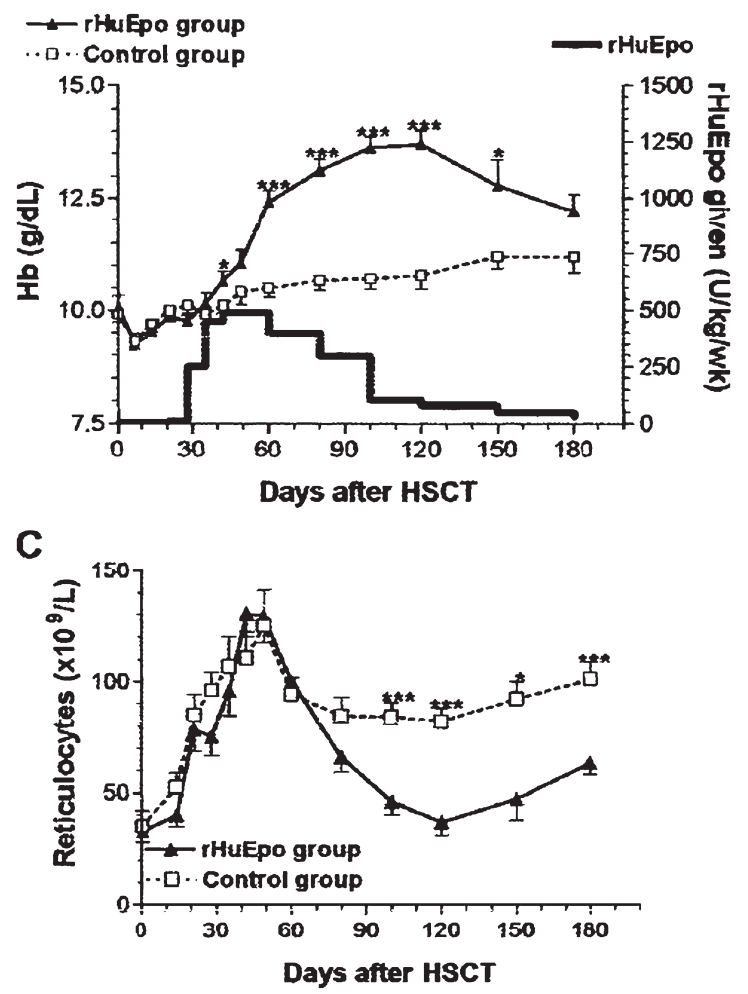

Fig. 3. Evolution of serum transferrin receptor (sTfR) levels (A), Hb levels (B), and reticulocyte counts (C) after autologous hematopoetic stem cell transplantation (HSCT) in 41 patients receiving rhEPO and 44 control patients without rhEPO. $p$ values are given for comparisons between rhEPO group and control group: *, $<0.05$; $* *,<0.01 ; * * *,<0.001$. (From Baron et al. (2003b) with permission) 
The efficacy of treatment with rhEPO started one month after autologous HSCT was then evaluated in a small prospective randomized trial including 10 patients with and 10 patients without rhEPO (Vanstraelen et al. 2005). After 3 weeks, $\mathrm{Hb}$ and serum transferring receptor levels were significantly $(\mathrm{p}<0.0001)$ higher in patients who received rhEPO compared with patients who did not. $\mathrm{Hb}$ response $(+2 \mathrm{~g} / \mathrm{dL})$ was $100 \%$ versus $28 \%(\mathrm{p}>0.0001)$ and $\mathrm{Hb}$ correction $(\geq 13 \mathrm{~g} / \mathrm{dL}) 70 \%$ versus $10 \%(\mathrm{p}=0.0238)$ in the two groups of patients, respectively. The rational use of rhEPO after autologous HSCT, as proposed here, should therefore renew interest in erythropoietin therapy. The results are impressive and suggest that autologous HSCT, similarly to allogeneic HSCT, is associated with the best response rate to rhEPO outside the setting of uremia. These trials now justify the development of prospective, randomized trials that should investigate clinical endpoints, such as transfusion requirements and quality of life, as well as cost-effectiveness.

\section{Comparative effects of rhEPO in autologous and allogeneic transplantation}

The generally negative results obtained in patients undergoing autologous BMT were confirmed in studies comparing the effects of rhEPO in autologous versus allogeneic transplants. Locatelli et al. (1994a) carried out a pilot study on the use of rhEPO in children undergoing allogeneic or purged autologous BMT for acute leukemia. RhEPO was given IV daily for a total of $725 \mathrm{U} / \mathrm{kg} / \mathrm{wk}$ from day 1 to day 30 post-transplant. In auto-BMT patients, there was no difference between 10 rhEPO patients and 10 historical controls for neutrophil, platelet or erythroid engraftment. There was no apparent stimulation of reticulocyte output, no increase in STfR at day 15 or at day 30 , and the numbers of platelet or RBC transfusions were not reduced. By contrast, rhEPO had a significant impact on erythroid engraftment in 10 alloBMT compared to 15 historical controls. Although the reticulocyte count was not different between the 2 groups at day 15, sTfR levels were already significantly elevated. This was confirmed at day 30 when the reticulocyte count was also higher than in the historical controls. As a result of faster erythroid engraftment, the number of red cell transfusions was reduced by half. Interestingly, although the median time to 500 neutrophils or to 50,000 platelets was not significantly affected by rhEPO therapy, the number of platelet transfusions was also cut by half.

Another comparison of the effect of rhEPO in autologous vs allogeneic transplantation was conducted by Link et al. (1994) in a prospective, randomized, double-blind, placebo-controlled multicenter trial (Table 5). After allo-BMT, 106 patients received rhEPO and 109 received placebo. After auto-BMT, there were 57 patients in each arm. Patients received rhEPO by continuous IV infusion for a total dose of $1,050 \mathrm{U} / \mathrm{kg} / \mathrm{wk}$ until day 41 or until independence from erythrocyte transfusions was achieved with a stable $\mathrm{Hb}$ 


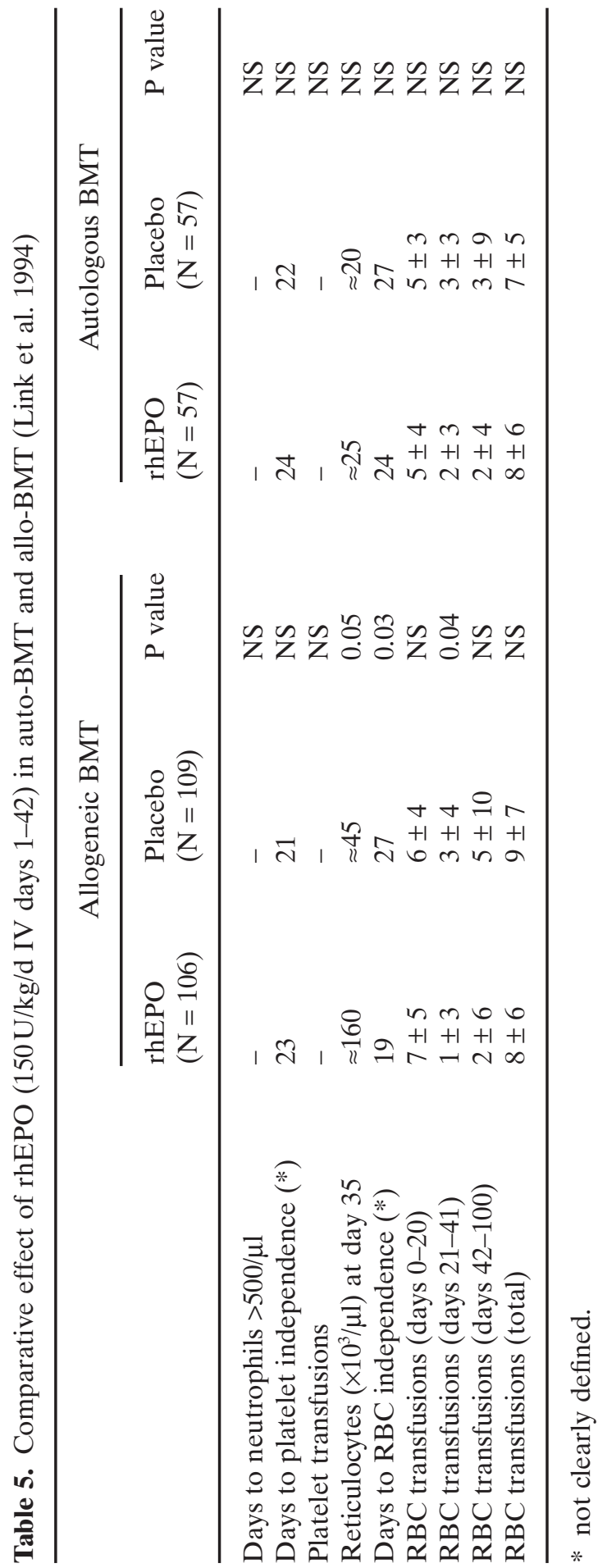


$>9 \mathrm{~g} / \mathrm{dl}$. Neither in allogeneic nor in autologous BMT was there any effect on the median times to 500 neutrophils or to platelet independence, and the number of platelet transfusions remained unchanged. In auto-BMT, there was no difference in the regeneration of reticulocytes, time to transfusion independence, and the number of RBC transfusions. After allo-BMT, reticulocyte counts were higher with rhEPO from day 21 to day 42 and median time to transfusion independence was significantly shortened by about onethird. Whereas the mean number of RBC transfusions was not different for the periods going from day 0 to day 20 or from day 42 to day 100 , there was a significant reduction between days 21 and 41. After day 20, rhEPO significantly reduced transfusion needs in these patient groups. The most spectacular effect was in patients with grade 3-4 GVHD in whom transfusion requirement decreased from $18 \pm 9$ to $9 \pm 7$ units. In allo-BMT, a multivariate analysis of time to erythrocyte transfusion independence showed that only treatment with rhEPO significantly reduced this time interval, while age, diagnosis, bleeding events, CMV infection, GVHD, T-cell depletion, ABO blood group incompatibility and HLA match or mismatch had no impact. A multivariate analysis of factors influencing the number of RBC transfusions from day 0 to 41 disclosed an impact only for bleeding events, severe GVHD, and major $\mathrm{ABO}$ blood group incompatibility, while treatment with rhEPO or placebo, age, diagnosis, CMV infection, T-cell depletion and HLA match or mismatch had no relevant influence. When the analysis was performed for the period from day 21 to 41, only rhEPO had a significant impact on transfusion needs, particularly in patients with severe GVHD, major ABO incompatibility or hemorrhage. In auto-BMT, only bone marrow purging significantly increased the time to transfusion independence, and rhEPO treatment, age, diagnosis, bleeding event or CMV infection had no influence. Several factors increased the number of transfusions: age older than 35 years, AML diagnosis, and bone marrow purging, but not bleeding events or CMV infection.

\section{RhEPO before transplantation}

As rhEPO therapy early after an autologous transplant does not appear to provide significant benefits, an alternative could be to raise the hemoglobin level before the transplant so that the risk of transfusion could be lowered. The success of such a strategy has first been reported by Estrin et al. (1997) in a Jehovah's Witness undergoing high-dose chemotherapy with PBPC transplantation for non-Hodgkin's lymphoma. De la Serna et al. (1999) reported a patient with acute promyelocytic leukemia scheduled for allogeneic transplantation, who had liver disease due to severe iron overload, previous drug toxicity and hepatitis $\mathrm{C}$ infection. In order to decrease the risk of severe liver toxicity, iron depletion was planned prior to transplantation. The patient was 
given low-dose rhEPO so as to facilitate 34 phlebotomies carried out over 9 months. This treatment markedly reduced iron stores to normal, normalized liver function tests, and effectively permitted to perform the transplant without significant liver toxicity.

This concept was extended by Ponchio et al. (2000) who treated 10 breast cancer patients with rhEPO 10,000 U tiw for 8 weeks before high-dose chemotherapy with PBPC transplantation. The hemoglobin increased by an average of $4 \mathrm{~g} / \mathrm{dL}$ and normalized in $8 / 10$ patients, resulting in levels $2.3 \mathrm{~g} / \mathrm{dL}$ higher than in 25 historical controls before high-dose chemotherapy. RBC transfusion needs after the transplant were significantly lower in the treatment group, with only 1 patient requiring a single 2-units transfusion. However, it should be emphasized that transfusion requirements in the historical groups were rather low and that this strategy did not appear to be cost-effective.

These results were confirmed by Hunault-Berger et al. (2005) who treated 11 consecutive patients with hematological diseases with rhEPO given during chemotherapy before 15 courses of HDT and autologous PBSCT. RhEPO was administered SC at a dose of 10,000 UI tiw for a maximum of 12 weeks before transplantation. Immediately before transplantation, mean $\mathrm{Hb}$ levels were significantly higher $(\mathrm{p}=0.002)$ in rhEPOtreated patients $(12.9 \pm 2.2 \mathrm{~g} / \mathrm{dL})$ than in 17 historical controls undergoing 22 courses of HDT and autologous PBSCT $(11.4 \pm 1.5 \mathrm{~g} / \mathrm{dL})$. RBC transfusion requirements fell from $95 \%(21 / 22)$ in historical controls to $26 \%(4 / 15)$ in rhEPO-treated patients $(\mathrm{p}=0.00001)$.

Baron et al. (2003c) examined a similar strategy, but after a first procedure of autologous transplantation. RhEPO was administered to 11 multiple myeloma patients undergoing tandem autologous PBSC transplantation, with the aim of avoiding RBC transfusions in the second HSCT procedure. RhEPO was not given prior to the first transplant, so that patients served as their own internal controls. Patients were scheduled to start rhEPO $(500 \mathrm{U} / \mathrm{kg} / \mathrm{wk})$ on day 30 after the first PBSCT. Median time to an Hb increment $>2 \mathrm{~g} / \mathrm{dL}$ was 4 weeks and 8 out of 11 patients achieved an $\mathrm{Hb}$ of $13 \mathrm{~g} / \mathrm{dL}$ after a median of 8 weeks. The $\mathrm{Hb}$ level increased from $9.6 \pm 1.0 \mathrm{~g} / \mathrm{dL}$ at baseline to $13.9 \pm 1.4 \mathrm{~g} / \mathrm{dL}$ on day $100(\mathrm{p}<0.001)$, compared to a change from 11.1 \pm 0.9 to $11.6 \pm 1.9 \mathrm{~g} / \mathrm{dL}$ in a historical control group. Hb values after the $2^{\text {nd }}$ transplant remained higher throughout the first 2 wks but on day 28 reached levels identical to those of the first transplant. Ten of 11 patients required RBC transfusions for the first PBSCT versus 1 of 11 for the second transplant $(\mathrm{p}<0.001)$. RBC and platelet requirements were $1.7 \pm 1.3$ and $1.0 \pm 1.1$ for the first versus $0.1 \pm 0.3(\mathrm{p}=0.003)$ and $0.5 \pm 0.7$ (NS) for the second procedure, respectively.

In conclusion, rhEPO treatment before high-dose chemotherapy appears as the most effective strategy to facilitate the performance of an autologous transplant without RBC transfusions. 


\section{RhEPO to mobilize PBSC}

Several investigators have studied the usefulness of rhEPO to mobilize hematopoietic progenitor cells into the peripheral blood for the purpose of PBSC collection. Kessinger et al. (1995) administered rhEPO 200 U/kg/day $\mathrm{SC}$ to 12 patients with relapsed malignancies. Steady-state collections were compared with aphereses started after 4 days of Epo administration and continued to a total of $6.5 \times 10^{8} \mathrm{MNC} / \mathrm{kg}$. After a median of 8 (range 5-14) aphereses the total progenitor cell doses collected were still low. Although there was no significant change in the percentage of CD34+ cells, there was a significant increase in BFU-E and CFU-GM, which culminated on the 5th day of Epo administration. Nine patients received Epo-mobilized PBSC after high-dose therapy and the median times to 500 neutrophils and last platelet transfusion were 16 and 24 days, respectively. No details are given on the high-dose chemotherapy regimen used. The same group (O'Kane-Murphy et al. 1994) evaluated the CD34 content of the Epo-mobilized PBSC products and found no correlation with the number of colony-forming cells. CD34+ cells were increased in some patients but others showed elevated CD34+ cell counts already before rhEPO administration.

Pettengell et al. (1994) gave rhEPO at a dose of 300-450 U/kg SC twice weekly for 2 weeks to 11 patients with untreated lymphoma. The total number of peripheral blood colonies increased 5-fold, including a 7-fold increase in CFU-GM, a 4-fold increase in BFU-E and a 2-fold increase in primitive BFU-E. While there was no change in CFU-MK or CFU-MIX numbers, the number of CD34 + cells increased also significantly. Maximal progenitor cell release was observed at days 5-8 but there was no return to baseline within the 15 days of study. Unfortunately, no change in long-term culture-initiating cells could be demonstrated. In the bone marrow, the only significant rise was in erythroid progenitors.

Although these studies demonstrate that rhEPO can somewhat mobilize progenitor cells into the peripheral blood of steady-state patients, this effect is much less pronounced thanthe one obtained with other agents such as G-CSF. However, the combination of rhEPO and G-CSF could prove to have synergistic effects. Ferrari et al. (1999) documented CD34 ${ }^{+}$progenitor cell mobilization with topotecan followed by the combination of G-CSF $(5 \mu \mathrm{g} / \mathrm{kg} / \mathrm{d})$ and $\mathrm{rhEPO}(10,000 \mathrm{IU} / \mathrm{d})$ starting $24 \mathrm{~h}$ after chemotherapy in 10 patients with small-cell lung cancer. Filip et al. (1997) administered G-CSF $(5 \mu \mathrm{g} / \mathrm{kg} / \mathrm{d})$ and $\mathrm{rhEPO}(250 \mathrm{IU} / \mathrm{kg} / \mathrm{d})$ to 11 consecutive breast carcinoma patients after priming with epirubicin and cyclophosphamide chemotherapy. The results show a significant mobilization of CD34 $4^{+}$cells, CFU-GM and BFU-E. Joshi et al. (2000) studied the functional and phenotypic properties of PBSC collected from 15 cancer patients mobilized with G-CSF $(10 \mu \mathrm{g} / \mathrm{kg} / \mathrm{d})$ $+\operatorname{rhEPO}(300 \mathrm{IU} / \mathrm{kg} / \mathrm{d})$. Only the first 4 apheresis collections from each patient were evaluated for this study. The results show that the combination of EPO + G-CSF not only mobilized hematopoietic precursor cells but also 
increased the number of myeloid cells, B-cells and NK cells in the peripheral blood.

Pierelli et al. (1994) tested the hypothesis in a comparison of PBSC mobilization after chemotherapy with either G-CSF alone or G-CSF + rhEPO. Although there were only 5 patients with ovarian carcinoma in each group, those receiving rhEPO at a dose of $150 \mathrm{U} / \mathrm{kg}$ SC every $48 \mathrm{~h}$ in addition to G-CSF $5 \mu \mathrm{g} / \mathrm{kg} /$ day SC for 13 days, had a significant increment of circulating CFU-GM and BFU-E whose peak value also occurred earlier. In addition, although there was no difference in neutrophil or platelet nadir, those patients receiving rhEPO had a significantly higher hematocrit nadir, which could facilitate PBSC collection without transfusion.

Olivieri et al. (1995) conducted a retrospective study in 34 patients to assess the effectiveness of the combination of $\mathrm{rhEPO}(50 \mathrm{U} / \mathrm{kg} / \mathrm{d})+\mathrm{G}-\mathrm{CSF}$ $(5 \mu \mathrm{g} / \mathrm{kg} / \mathrm{d})(\mathrm{n}=16)$ starting $24 \mathrm{~h}$ after priming chemotherapy, compared to the results obtained by G-CSF alone $(n=18)$. The duration of post-priming neutropenia was similar in the 2 groups. The combination of Epo and G-CSF was more effective than G-CSF alone, with a median of 1.9-fold increase for circulating MNC, 4.0-fold for CFU-GM, 4.7-fold for BFU-E and 2.8-fold for CD34+ cells. The differences were statistically significant both for mobilization and collection.

Waller et al. (1999) then carried out a prospective randomized trial in 32 patients with newly diagnosed stage II-IV breast cancer. Mobilization and harvest of PBSC followed cycle 2 of VIP-E chemotherapy. Sixteen patients were randomized to G-CSF $(5 \mu \mathrm{g} / \mathrm{kg})+\operatorname{rhEPO}(150 \mathrm{IU} / \mathrm{kg})$ and 14 patients to G-CSF alone, starting day 1 after chemotherapy. There was no significant difference with regard to $\mathrm{CD} 34+$ cell kinetics in peripheral blood or $\mathrm{MNC}$, CD34+ cells, BFU-E and CFU-GM in apheresis products. Transplantation of $>1 \times 10^{6} \mathrm{CD} 34^{+}$cells $/ \mathrm{kg}$ after high-dose chemotherapy resulted in similar hematological recovery of the two groups.

In another prospective randomized trial, Pierelli et al. (1999) included 50 ovarian cancer patients to mobilize PBSC after a first course of ETP chemotherapy using either G-CSF $(5 \mu \mathrm{g} / \mathrm{kg} / \mathrm{d})$ or G-CSF plus rhEPO $(150 \mathrm{IU} / \mathrm{kg}$ every $48 \mathrm{~h})$ from day 2 to day 13 . The addition of rhEPO to G-CSF increased PBSC mobilization $(\mathrm{p}=0.0009)$ and collection $(\mathrm{p}=0.0026)$. Patients receiving G-CSF alone required a significantly $(p=0.0076)$ higher number of leukaphereses to obtain the planned minimum dose of CD34+ cells. However, the number of CFU-GM and BFU-E was not different. Fortytwo patients underwent transplants after high-dose chemotherapy with the CEM regimen. The first 18 patients received reinfusions of a fixed dose of 4 $\times 10^{6} / \mathrm{kg}$ of G-CSF (9 patients) or G-CSF + EPO (9 patients) mobilized CD34+ cells to allow formal comparison of the in vivo functional properties of the collected PBSC. Trilineage hematopoietic recovery was identical. The subsequent 24 patients were given reinfusions of the entire G-CSF (12 patients) or G-CSF + EPO (12 patients) mobilized products to evaluate the in vivo hematopoietic potential of the entire graft. Despite higher CD34+ cell 
dose in the G-CSF + EPO arm, neutrophil and erythroid recovery (including number of RBC transfusions) were similar, although platelet engraftment occurred one day earlier and number of platelet transfusions was reduced from 1.4 to 0.5 per patient.

Perillo et al. (2001) conducted a randomized comparison of the mobilizing capacity of G-CSF + EPO versus sequential GM-/G-CSF + EPO following a first cycle of ETP chemotherapy (epirubicin, paclitaxel and cisplatin) in ovarian cancer patients. Twenty patients received G-CSF $(5 \mu \mathrm{g} / \mathrm{kg} / \mathrm{d})$ from day 2 to day 13 and 20 patients received GM-CSF $(5 \mu \mathrm{g} / \mathrm{kg} / \mathrm{d})$ from day 2 to day 6 followed by G-CSF $(5 \mu \mathrm{g} / \mathrm{kg} / \mathrm{d})$ from day 7 to day 13 . RhEPO was administered every other day from day 2 to day 13 at a dose of $150 \mathrm{IU} / \mathrm{kg}$ in both arms. Although CD34+ cell mobilization into the peripheral blood was comparable, GM-/G-CSF+EPO patients had significantly higher CD34+ cell yields because of higher CD34+ cell collection efficiency. However, numbers of CFU-GM, BFU-E and LTC-IC collected were identical in the two arms. Identical doses of PBSC mobilized by GM-/G-CSF+EPO or G-CSF+EPO resulted in comparable hematopoietic recovery after reinfusion in patients treated with identical high-dose chemotherapy.

Therefore, although one randomized trial suggests synergistic effects of the combination of G-CSF and Epo for mobilization of autologous PBSC, others do not and this strategy has not been shown to result in significant acceleration of engraftment after autologous transplantation. Furthermore, a note of caution was derived from the only study that investigated PBSC mobilization in normal donors for allogeneic use. Sautois et al. (2001) administered rhEPO $(600 \mathrm{IU} / \mathrm{kg})$ twice weekly with IV iron $(200 \mathrm{mg})$ supplementation for 3 weeks to normal donors and collected RBC units. G-CSF was added in the last 5 days and PBSC were collected and infused into their respective recipients. The administration of rhEPO alone for 2.5 weeks was not associated with any significant increase of circulating $\mathrm{WBC}, \mathrm{CD} 34^{+}$cells or progenitor cell numbers over baseline. Compared to 10 donor/recipient pairs receiving G-CSF alone for PBSC mobilization, the cumulative yields of $\mathrm{NC}$ and CFU-GM were significantly lower in the study group while those of BFU-E, CFU-Mix and CD $34^{+}$cells were similar. However, neutrophil and platelet engraftment were similar, while erythroid recovery was significantly accelerated in the study group because rhEPO was then administered also post-transplant. These results do not support synergistic effects of G-CSF and Epo for PBSC mobilization in normal donors, and may even suggest deleterious effects.

\section{Administration of rhEPO to donors}

Another interesting use of rhEPO in the setting of HSCT could be its administration to normal donors. This approach could benefit both the donor and 
the recipient. In the donor, this could preclude the need for autologous blood collection and, more importantly, enable donors in whom autologous blood cannot be obtained to avoid homologous blood exposure. This would be most beneficial to children or anemic donors. This approach would also benefit the recipient by priming the allograft to increase the number of Epo-responsive progenitors and by increasing blood donation by the donor for subsequent use by the recipient.

York et al. (1992) selected 2 children and 8 adults who either weighed less than $30 \mathrm{~kg}$ and did not have a unit of autologous blood stored or had a unit of blood stored but were anemic or were projected to have an operative blood loss exceeding $15 \mathrm{ml} / \mathrm{kg}$. These donors received 9-22 daily SC injections of $100 \mathrm{U} / \mathrm{kg}$ of rhEPO as well as oral iron. Between baseline and preoperative hematocrit, there was a $16 \%$ increase in the rhEPO group as compared to a $4 \%$ decrement in the control group. Between baseline and postoperative hematocrit, there was a significantly lower decrement in the rhEPO group than in controls ( $4 \%$ vs $26 \%$ ). After marrow harvest, rhEPO could be continued safely at a dose of $150 \mathrm{U} / \mathrm{kg}$ SC three times a week for 2 weeks or until the hematocrit reached $40 \%$. Akiyama (Akiyama et al. 1994) gave $100 \mathrm{U} / \mathrm{kg}$ SC rhEPO 3 times a week for 3 weeks to 4 bone marrow donors who had less than $13 \mathrm{~g} / \mathrm{dl}$ of $\mathrm{Hb} 3$ weeks before marrow donation. As compared to control donors, preoperative and postoperative $\mathrm{Hb}$ levels were significantly higher but the proportion of erythroid cells in the harvested marrow was unchanged. Martinez et al. (1998) administered rhEPO to 11 healthy bone marrow donors weighing less than $30 \mathrm{~kg}$. Three weeks before harvesting, the donors received $100 \mathrm{IU} / \mathrm{kg} / \mathrm{d} \mathrm{rhEPO}$ and oral iron supplementation. Hematocrit before harvesting increased by $10.6 \pm 1.3 \%$ above baseline value. Six children with subnormal $\mathrm{Hb}$ after harvesting received rhEPO $150 \mathrm{IU} / \mathrm{kg}$ tiw for two weeks. No patient required transfusion during or after bone marrow harvest. On day 15 after bone marrow collection, all donors but one had a Hct value = baseline value.

Mitus et al. (1994) exploited the fact that donor blood becomes autologous to the recipient graft by virtue of the transplant. Donors received oral iron and SC rhEPO at $300 \mathrm{U} / \mathrm{kg}$ five days per week beginning 3 weeks before transplant and continuing for 2 weeks afterwards. One unit of red blood cells was obtained twice weekly if hematocrit was $\geq 33 \%$. A median of 6 units (range 4 to 11 units) were collected. Five of the 11 donors received one or 2 units of autologous blood and none required homologous blood. The number of MNC obtained at marrow harvest was greater in the rhEPO-treated group. Recipients received rhEPO at $200 \mathrm{U} / \mathrm{kg}$ IV daily for 28 days and transfusions were administered at the discretion of the physicians. There was no difference in neutrophil and platelet engraftment nor in platelet transfusions between rhEPO-treated and control recipients. Although the time to reticulocytes $\geq 10,000 / \mu$ was shorter with the use of rhEPO, the mean total number of RBC transfusions was the same as in controls. However, rhEPO patients 
received only $5 \pm 6$ RBC units vs $8 \pm 6$ in controls (n.s.). Six of 11 rhEPOtreated recipients received only donor-derived blood, compared with 0 of 11 in the control group. However, taking into account platelet transfusions, total exposure to homologous blood was not diminished by rhEPO as administered in this study.

Sautois et al. (2001) took this approach further, this time with PBSC donors rather than marrow donors. RhEPO (600 IU $/ \mathrm{kg}$ ) was administered twice weekly with IV iron ( $200 \mathrm{mg}$ ) supplementation for 3 weeks before and 3 weeks after the transplant to 8 ABO-compatible donors. A red blood cell (RBC) unit was collected at each visit, so that up to $12 \mathrm{RBC}$ units per donor were available for use in their recipient. These recipients were treated with $200 \mathrm{IU} / \mathrm{kg} / \mathrm{d}$ IV rhEPO until they reached an unsupported hematocrit $\geq 30 \%$. Ninety-five percent of planned RBC units were collected in the donors without significant Hct decrease because of a 4-fold increase in RBC production. Erythroid recovery was significantly accelerated in the study group and RBC transfusion independence was achieved after a median of 21 (7-29) days in the study group vs $40(21-110)$ days in the control group $(\mathrm{p}=0.0007)$. The total numbers of RBC units transfused were not significantly different between the 2 groups, but the number of unrelated RBC units transfused was dramatically lower ( 2 vs $15, \mathrm{p}=0.026$ ) in the study group. However, some $\mathrm{RBC}$ units were not used and the difficult logistics and high cost of the procedure precludes widespread use of this strategy.

\section{Side effects of rhEPO administration in HSCT}

None of the studies performed in the setting of HSCT reported an increased incidence of side effects, such as hypertension or other cardiovascular events. In particular, there was no evidence of "stem cell steal" by which the stimulation of the erythroid compartment would be detrimental to the engraftment or maintenance of cells in other lineages. However, few studies were large enough to fully address the short-term and long-term safety of erythropoietin therapy after HSCT.

Van den Bent (van den Bent et al. 1999) reported a bone marrow transplant patient who developed visual hallucination episodes in the context of hypertension after administration of rhEPO, with full recovery after discontinuation. T2-weighted magnetic resonance imaging showed increased signal in the occipital white matter of both hemispheres, in the periventricular white matter and in the cerebellar hemisphere. These characteristic lesions were typical of posterior leukoencephalopathy syndrome.

Mann et al. (1996) reported the effect of erythropoietin administration on immunity in murine bone marrow chimeras. Half of the mice received 3 injections per week of Epo (12 UI), whereas the others received vehicle for 7 weeks starting 48 hours after transplantation. There was no significant alter- 
ation in lymphocyte numbers, although a nonsignificant shift in lymphocytes toward $\mathrm{T}$ cell predominance was observed. RhEPO administration resulted in enhanced cell proliferation in response to $\mathrm{T}$ and $\mathrm{B}$ cell mitogens, although no alteration in cytotoxicity or natural killer cell activity was observed. It is unknown whether these observations would be relevant in human transplantation.

\section{Summary}

Anemia is almost universal after allogeneic and autologous HSCT. After allogeneic, but less so after autologous transplantation, this is in large part due to defective endogenous EPO production that starts about one month after transplantation. In this group of patients, the use of rhEPO from transplantation to engraftment has been shown to accelerate the recovery of erythropoiesis and to shorten the time to transfusion independence and to reduce $\mathrm{RBC}$ transfusions in some but not all studies. In patients receiving autologous HSCT, such a benefit has not been shown. Recent studies, however, indicate that in this group of patients as well as in those receiving allogeneic HSCT, the results could markedly improve when treatment with rhEPO would only start after initial engraftment (i.e. after day 30 ), when endogenous EPO production becomes defective, and not immediately after the transplant. Recent studies also show that in the autologous setting, treatment with rhEPO before HD chemotherapy may be an effective strategy to facilitate the performance of a HSCT without RBC transfusions. The role of rhEPO in stem cell mobilization has not yet been conclusively defined.

\section{References}

1. Abedi MR, Backman L, Bostrom L, Lindback B, Ringden O (1990) Markedly increased serum erythropoietin levels following conditioning for allogeneic bone marrow transplantation. Bone Marrow Transplant 6: 121-126

2. Akiyama H, Tanikawa S, Takamoto S, Sakamaki H, Sasaki T, Onozawa Y (1994) Recombinant human erythropoietin (EPO) administration to marrow donors. Blood 84 [Suppl 1]: 732a (Abstract)

3. Ayash LJ, Elias A, Hunt M, Demetri G, Wheeler C, Tepler I, Schwartz G, Mazanet R, Reich E, McCauley M, Antman K, Anderson KC (1994) Recombinant human erythropoietin for the treatment of the anaemia associated with autologous bone marrow transplantation. Br J Haematol 87: 153-161

4. Baron F, Beguin Y (2002a) Nonmyeloablative allogeneic hematopoietic stem cell transplantation. J Hematother Stem Cell Res 11: 243-263

5. Baron F, Fillet G, Beguin Y (2002b) Erythropoiesis after nonmyeloablative stemcell transplantation is not impaired by inadequate erythropoietin production as observed after conventional allogeneic transplantation. Transplantation 74: 1692-1696 
6. Baron F, Frere P, Beguin Y (2003a) Once weekly recombinant human erythropoietin therapy is very efficient after allogeneic peripheral blood stem cell transplantation when started soon after engraftment. Haematologica 88: 718-720

7. Baron F, Frere P, Fillet G, Beguin Y (2003b) Recombinant human erythropoietin therapy is very effective after an autologous peripheral blood stem cell transplant when started soon after engraftment. Clin Cancer Res 9: 5566-5572

8. Baron F, Frere P, Fillet G, Beguin Y (2003c) Tandem high-dose therapy (HDT) for multiple myeloma: recombinant human erythropoietin therapy given between first and second HDT allows second peripheral blood stem cell transplantation without red blood cell transfusion. Br J Haematol 123: 103-105

9. Vanstraelen G, Baron F, Frere P, Hafraoui K, Fillet G, Beguin Y (2005) Efficacy of recombinant human erythropoietin therapy started one month after autologous peripheral blood stem cell transplantation. Haematologica 90: 1269-1270

10. Baron F, Sautois B, Baudoux E, Matus G, Fillet G, Beguin Y (2002c) Optimization of recombinant human erythropoietin therapy after allogeneic hematopoietic stem cell transplantation. Exp Hematol 30: 546-554

11. Beguin Y, Baron F, Fillet G (1998) Influence of marrow erythropoietic activity on serum erythropoietin levels after autologous hematopoietic stem cell transplantation. Haematologica 83: 1076-1081

12. Beguin Y, Clemons GK, Oris R, Fillet G (1991) Circulating erythropoietin levels after bone marrow transplantation: Inappropriate response to anemia in allogeneic transplants. Blood 77: 868-873

13. Beguin Y, Oris R, Fillet G (1993) Dynamics of erythropoietic recovery after bone marrow transplantation: role of marrow proliferative capacity and erythropoietin production in autologous versus allogeneic transplants. Bone Marrow Transplant 11: 285-292

14. Benedetti PP, Pierelli L, Scambia G, Foddai ML, Salerno MG, Menichella G, Vittori M, Maneschi F, Caracussi U, Serafini R, Leone G, Mancuso S (1997) Highdose carboplatin, etoposide and melphalan (CEM) with peripheral blood progenitor cell support as late intensification for high-risk cancer: non-haematological, haematological toxicities and role of growth factor administration. Br J Cancer 75: 1205-1212

15. Biggs JC, Atkinson KA, Booker V, Concannon A, Dart GW, Dodds A, Downs K, Szer J, Turner J, Worthington R (1995) Prospective randomised double-blind trial of the in vivo use of recombinant human erythropoietin in bone marrow transplantation from HLA-identical sibling donors. the Australian Bone Marrow Transplant Study Group. Bone Marrow Transplant 15: 129-134

16. Birgegard G, Wide L, Simonsson B (1989) Marked erythropoietin increase before fall in $\mathrm{Hb}$ after treatment with cytostatic drugs suggests mechanism other than anaemia for stimulation. Br J Haematol 72: 462-466

17. Bosi A, Vannucchi AM, Grossi A, Guidi S, Saccardi R, Rafanelli D, Longo G, Ferrini PR (1991a) Inadequate erythropoietin production in allogeneic bone marrow transplant patients. Haematologica 76: 280-284

18. Bosi A, Vannucchi AM, Grossi A, Guidi S, Vannucchi L, Saccardi R, Bernabei PA, Longo G, Rafanelli D, Rossi Ferrini P (1991b) Serum erythropoietin levels in patients undergoing autologous bone marrow transplantation. Bone Marrow Transplant 7: 421-425

19. Bowen DT, Janowska-Wieczorek A (1990) Serum erythropoietin following cytostatic therapy [letter]. Br J Haematol 74: 372-373 
20. Cazzola M, Guarnone R, Cerani P, Centenara E, Rovati A, Beguin Y (1998) Red blood cell precursor mass as an independent determinant of serum erythropoietin level. Blood 91: 2139-2145

21. Chao NJ, Schriber JR, Long GD, Negrin RS, Catolico M, Brown BW, Miller LL, Blume KG (1994) A randomized study of erythropoietin and granulocyte colonystimulating factor (G-CSF) versus placebo and G-CSF for patients with Hodgkin's and non-Hodgkin's lymphoma undergoing autologous bone marrow transplantation. Blood 83: 2823-2828

22. Chuncharunee S, Carter CD, Studtmann KE, Caro J, Coffey RJ, Dessypris EN (1993) Chronic administration of transforming growth factor-beta suppresses erythropoietin-dependent erythropoiesis and induces tumour necrosis factor in vivo. Br J Haematol 84: 374-380

23. Davies SV, Fegan CD, Kendall R, Beguin Y, Cavill I (1995) Serum erythropoietin during autologous bone marrow transplantation: relationship to measures of erythroid activity. Clin Lab Haematol 17: 139-144

24. de la Serna J, Bornstein R, Garcia-Bueno MJ, Lahuerta-Palacios JJ (1999) Iron depletion by phlebotomy with recombinant erythropoietin prior to allogeneic transplantation to prevent liver toxicity. Bone Marrow Transplant 23: 95-97

25. Erslev AJ (1991) Erythropoietin titers in health and disease. Semin Hematol 28 [Suppl 3]: 2-7

26. Eschbach JW, Egrie JC, Downing MR, Browne JK, Adamson JW (1987) Correction of the anemia of end-stage renal disease with recombinant human erythropoietin. N Engl J Med 316: 73-78

27. Estrin JT, Ford PA, Henry DH, Stradden AP, Mason BA (1997) Erythropoietin permits high-dose chemotherapy with peripheral blood stem-cell transplant for a Jehovah's Witness [letter]. Am J Hematol 55: 51-52

28. Fandrey J, Jelkmann WE (1991) Interleukin-1 and tumor necrosis factor-alpha inhibit erythropoietin production in vitro. Ann NY Acad Sci 628: 250-255

29. Faquin WC, Schneider TJ, Goldberg MA (1992) Effect of inflammatory cytokines on hypoxia-induced erythropoietin production. Blood 79: 1987-1994

30. Ferrara JL, Cooke KR, Teshima T (2003) The pathophysiology of acute graftversus-host disease. Int J Hematol 78: 181-187

31. Ferrari S, Danova M, Porta C, Comolli G, Brugnatelli S, Pugliese P, Riccardi A, Ascari E (1999) Circulating progenitor cell release and functional characterization after topotecan plus G-CSF and erythropoietin in small cell lung cancer patients. Int J Oncol 15: 811-815

32. Filip S, Vanasek J, Blaha M, Mericka P, Vavrova J, Podzimek K (1999) The increase of the rate of hemopoietic recovery and clinical benefit of the erythropoietin (EPO) and granulocyte colony-stimulating factor (G-CSF) with peripheral blood progenitor cells (PBPC) after intensive cyclic chemotherapy in high-risk breast cancer patients. Neoplasma 46: 166-172

33. Filip S, Vanasek J, Blaha M, Vavrova J (1997) Circulation of progenitor cells after intensive chemotherapy followed by combination G-CSF and EPO in breast carcinoma. Neoplasma 44: 212-218

34. Frede S, Fandrey J, Pagel H, Hellwig T, Jelkmann W (1997) Erythropoietin gene expression is suppressed after lipopolysaccharide or interleukin-1 beta injections in rats. Am J Physiol 273: R1067-R1071

35. Fujimori Y, Kanamaru A, Saheki K, Mori A, Takatsuka H, Wada H, Okada M, Tamura S, Okamoto T, Takemoto Y, Kakishita E, Nagai K (1998) Recombinant 
human erythropoietin for late-onset anemia after allogeneic bone marrow transplantation. Int J Hematol 67: 131-136

36. Fujisawa S, Maruta A, Sakai R, Taguchi J, Tomita N, Ogawa K, Kodama F, Takahashi K, Shibayama S, Kobayashi S, Ikuta K, Okubo T (1996) Pure red cell aplasia after major $\mathrm{ABO}$-incompatible bone marrow transplantation: two case reports of treatment with recombinant human erythropoietin. Transpl Int 9: 506-508

37. Grace RJ, Kendall RG, Chapman C, Hartley AE, Barnard DL, Norfolk DR (1991) Changes in serum erythropoietin levels during allogeneic bone marrow transplantation. Eur J Haematol 47: 81-85

38. Heyll A, Aul C, Runde V, Arning M, Schneider W, Wernet P (1991) Treatment of pure red cell aplasia after major ABO-incompatible bone marrow transplantation with recombinant erythropoietin [letter]. Blood 77: 906

39. Hunault-Berger M, Tanguy-Schmidt A, Rachieru P, Levy V, Truchan-Graczyk M, Francois S, Gardembas-Pain M, Dib M, Foussard C, Piard N, Godon A, SolalCeligny P, Ifrah N (2005) rHuEpo before high-dose therapy allows autologous peripheral stem-cell transplantation without red blood cell transfusion: a pilot study. Bone Marrow Transplant 35: 903-907

40. Ireland RM, Atkinson K, Concannon A, Dodds A, Downs K, Biggs JC (1990) Serum erythropoietin changes in autologous and allogeneic bone marrow transplant patients. Br J Haematol 76: 128-134

41. Jelkmann W, Pagel H, Wolff M, Fandrey J (1992) Monokines inhibiting erythropoietin production in human hepatoma cultures and in isolated perfused rat kidneys. Life Sci 50: 301-308

42. Jelkmann W, Wolff M, Fandrey J (1990) Modulation of the production of erythropoietin by cytokines: in vitro studies and their clinical implications. Contrib Nephrol 87: 68-77

43. Joshi SS, Miller K, Jackson JD, Warkentin P, Kessinger A (2000) Immunological properties of mononuclear cells from blood stem cell harvests following mobilization with erythropoietin + G-CSF in cancer patients. Cytotherapy 2: 15-24

44. Kessinger A, Bishop MR, Jackson JD, O'Kane-Murphy B, Vose JM, Bierman PJ, Reed EC, Warkentin PI, Armitage JO, Sharp JG (1995) Erythropoietin for mobilization of circulating progenitor cells in patients with previously treated relapsed malignancies. Exp Hematol 23: 609-612

45. Klaesson S, Ringden O, Ljungman P, Lonnqvist B, Wennberg L (1994a) Reduced blood transfusions requirements after allogeneic bone marrow transplantation: results of a randomised, double-blind study with high-dose erythropoietin. Bone Marrow Transplant 13: 397-402

46. Klaesson S, Ringden O, Ljungman P, Lonnqvist B, Wennberg L (1994b) Treatment with erythropoietin after allogeneic bone marrow transplantation: a randomized, double-blind study. Transplant Proc 26: 1827-1828

47. Lacey SF, Diamond DJ, Zaia JA (2004) Assessment of cellular immunity to human cytomegalovirus in recipients of allogeneic stem cell transplants. Biol Blood Marrow Transplant 10: 433-447

48. Lazarus HM, Goodnough LT, Goldwasser E, Long G, Arnold JL, Strohl KP (1992) Serum erythropoietin levels and blood component therapy after autologous bone marrow transplantation: implications for erythropoietin therapy in this setting. Bone Marrow Transplant 10: 71-75 
49. Lin AC, Goldwasser E, Bernard EM, Chapman SW (1990) Amphotericin B blunts erythropoietin response to anemia. J Infect Dis 161: 348-351

50. Link H, Boogaerts MA, Fauser AA, Slavin S, Reiffers J, Gorin NC, Carella AM, Mandelli F, Burdach S, Ferrant A, Linkesch W, Tura S, Bacigalupo A, Schindel F, Heinrichs H (1994) A controlled trial of recombinant human erythropoietin after bone marrow transplantation. Blood 84: 3327-3325

51. Link H, Brune T, Hubner G, Diedrich H, Freund M, Stoll M, Peest D, Ebell W, Bettoni C, Oster W, Nicolay U, Heinrichs H (1993) Effect of recombinant human erythropoietin after allogenic bone marrow transplantation. Ann Hematol 67: 169-173

52. Locatelli F, Pedrazzoli P, Barosi G, Zecca M, Porta F, Liberato L, Gambarana D, Nespoli L, Cazzola M (1992) Recombinant human erythropoietin is effective in correcting erythropoietin-deficient anaemia after allogeneic bone marrow transplantation. Br J Haematol 80: 545-549

53. Locatelli F, Zecca M, Beguin Y, Giorgiani G, Ponchio L, De Stefano P, Cazzola M (1993) Accelerated erythroid repopulation with no stem-cell competition effect in children treated with recombinant human erythropoietin after allogeneic bone marrow transplantation. Br J Haematol 84: 752-754

54. Locatelli F, Zecca M, Pedrazzoli P, Prete L, Quaglini S, Comoli P, De Stefano P, Beguin Y, Robustelli della Cuna G, Severi F, Cazzola M (1994a) Use of recombinant human erythropoietin after bone marrow transplantation in pediatric patients with acute leukemia: effect on erythroid repopulation in autologous versus allogeneic transplants. Bone Marrow Transplant 13: 403-410

55. Locatelli F, Zecca M, Ponchio L, Beguin Y, Giorgiani G, Maccario R, Bonetti F, De Stephano P, Cazzola M (1994b) Pilot trial of combined administration of erythropoietin and granulocyte colony-stimulating factor to children undergoing allogeneic bone marrow transplantation. Bone Marrow Transplant 14: 929935

56. Lopez J, Steegmann JL, Perez G, Otero MJ, Berberana M, Camara R, Lamana M, Fernandez Villalta MJ, Fernandez-Ranada JM (1994) Erythropoietin in the treatment of delayed immune hemolysis of a major ABO-incompatible bone marrow transplant. Am J Hematol 45: 237-239

57. Mann RA, Jetzt AE, Singh M, Singh AB (1996) The effect of erythropoietin administration on murine bone marrow chimeras. Immunol Lett 49: 15-20

58. Martelli M, Ponchio L, Beguin Y, Meloni G, Mandelli F, Cazzola M (1994) Pure red cell aplasia following peripheral stem cell transplantation: complete response to a short course of high-dose recombinant human erythropoietin. Haematologica 79: $456-459$

59. Martinez AM, Sastre A, Munoz A, Badell I, Maldonado MS, Cubells J (1998) Recombinant human erythropoietin (rh-Epo) administration to normal child bone marrow donors. Bone Marrow Transplant 22: 137-138

60. Miller CB, Jones RJ, Zahurak ML, Piantadosi S, Burns WH, Santos GW, Spivak JL (1992a) Impaired erythropoietin response to anemia after bone marrow transplantation. Blood 80: 2677-2682

61. Miller CB, Mills S (1994) Erythropoietin after bone marrow transplantation. Hematol Oncol Clin North Am 8: 975-992

62. Miller KL, Carlino JA, Ogawa Y, Avis PD, Carroll KG (1992b) Alterations in erythropoiesis in TGF-beta 1-treated mice. Exp Hematol 20: 951-956 
63. Mitus AJ, Antin JH, Rutherford CJ, McGarigle CJ, Goldberg MA (1994) Use of recombinant human erythropoietin in allogeneic bone marrow transplant donor/ recipient pairs. Blood 83: 1952-1957

64. Nguyen VA, Fauser AA, Basara N, Kiehl M (2003) Erythropoietic recovery during treatment with darbepoietin-alpha after impaired $\mathrm{rHuEPO}$ response to anemia in two patients with osteomyelofibrosis after peripheral blood stem cell transplantation. Hematol J 4: 456-458

65. Nieken J, Mulder NH, Buter J, Vellenga E, Limburg PC, Piers DA, de Vries EG (1995) Recombinant human interleukin-6 induces a rapid and reversible anemia in cancer patients. Blood 86: 900-905

66. O'Kane-Murphy B, Jackson JD, Kuszynski C, Costas P, Wang PN, Warkentin PI, Kessinger A (1994) CD34 analysis in erythropoietin mobilized peripheral blood stem cells. Prog Clin Biol Res 389: 371-376

67. Ohashi K, Akiyama H, Takamoto S, Tanikawa S, Sakamaki H, Onozawa Y (1994) Treatment of pure red cell aplasia after major ABO-incompatible bone marrow transplantation resistant to erythropoietin. Bone Marrow Transplant 13: 335336

68. Olivieri A, Offidani M, Cantori I, Ciniero L, Ombrosi L, Masia MC, Brunori M, Montroni M, Leoni P (1995) Addition of erythropoietin to granulocyte colonystimulating factor after priming chemotherapy enhances hemopoietic progenitor mobilization. Bone Marrow Transplant 16: 765-770

69. Olivieri A, Scortechini I, Capelli D, Montanari M, Lucesole M, Gini G, Troiani M, Offidani M, Poloni A, Masia MC, Raggetti GM, Leoni P (2004) Combined administration of alpha-erythropoietin and filgrastim can improve the outcome and cost balance of autologous stem cell transplantation in patients with lymphoproliferative disorders. Bone Marrow Transplant 34: 693-702

70. Paltiel O, Cournoyer D, Rybka W (1993) Pure red cell aplasia following ABOincompatible bone marrow transplantation: response to erythropoietin. Transfusion 33: 418-421

71. Pedrazzini A (1993) Erythropoietin and GM-CSF following autologous bone marrow transplantation. Eur J Cancer 29 [Suppl 2]: S15-S17

72. Pene R, Appelbaum FR, Fisher L, Lilleby K, Nemunaitis J, Storb R, Buckner CD (1993) Use of granulocyte-macrophage colony-stimulating factor and erythropoietin in combination after autologous marrow transplantation. Bone Marrow Transplant 11: 219-222

73. Perillo A, Pierelli L, Battaglia A, Salerno MG, Rutella S, Cortesi E, Fattorossi A, De Rosa L, Ferrau F, Lalle M, Leone G, Mancuso S, Scambia G (2002) Administration of low-dose interleukin-2 plus G-CSF/EPO early after autologous PBSC transplantation: effects on immune recovery and NK activity in a prospective study in women with breast and ovarian cancer. Bone Marrow Transplant 30: 571-578

74. Perillo A, Pierelli L, Scambia G, Serafini R, Paladini U, Salerno MG, Bonanno G, Fattorossi A, Leone G, Mancuso S, Menichella G (2001) Peripheral blood progenitor cell collection after epirubicin, paclitaxel, and cisplatin combination chemotherapy using EPO-based cytokine regimens: a randomized comparison of G-CSF and sequential GM-/G-CSF. Transfusion 41: 674-680

75. Pettengell R, Woll PJ, Chang J, Coutinho L, Testa NG, Crowther D (1994) Effects of erythropoietin on mobilisation of haemopoietic progenitor cells. Bone Marrow Transplant 14: 125-130 
76. Pierelli L, Menichella G, Scambia G, Teofili L, Iovino S, Serafini R, Benedetti Panici P, Salerno G, Rumi C, Zini G, d'Onofrio G, Leone G, Mancuso S, Bizzi B (1994) In vitro and in vivo effects of recombinant human erythropoietin plus recombinant human G-CSF on human haemopoietic progenitor cells. Bone Marrow Transplant 14: 23-30

77. Pierelli L, Perillo A, Greggi S, Salerno G, Panici PB, Menichella G, Fattorossi A, Leone G, Mancuso S, Scambia G (1999) Erythropoietin addition to granulocyte colony-stimulating factor abrogates life-threatening neutropenia and increases peripheral-blood progenitor-cell mobilization after epirubicin, paclitaxel, and cisplatin combination chemotherapy: results of a randomized comparison. J Clin Oncol 17: 1288-1295

78. Pierelli L, Scambia G, Menichella G, d'Onofrio G, Salerno G, Panici PB, Foddai ML, Vittori M, Lai M, Ciarli M, Puglia G, Mancuso S, Bizzi B (1996) The combination of erythropoietin and granulocyte colony-stimulating factor increases the rate of haemopoietic recovery with clinical benefit after peripheral blood progenitor cell transplantation. Br J Haematol 92: 287-294

79. Ponchio L, Zambelli A, De Stefano A, Robustelli Della Cuna FS, Perotti C, Pedrazzoli P (2000) Transfusion requirement can be abolished by epoietin- $\alpha$ and autologous platelet predeposit in patients receiving high dose chemotherapy with stem cell support [letter]. Haematologica 85: 219-220

80. Santamaria A, Sureda A, Martino R, Domingo-Albos A, Muniz-Diaz E, Brunet S (1997) Successful treatment of pure red cell aplasia after major ABO-incompatible $\mathrm{T}$ cell-depleted bone marrow transplantation with erythropoietin. Bone Marrow Transplant 20: 1105-1107

81. Sautois B, Baudoux E, Salmon JP, Michaux S, Schaaf-Lafontaine N, Pereira M, Paulus JM, Fillet G, Beguin Y (2001) Administration of erythropoietin and granulocyte colony-stimulating factor in donor/recipient pairs to collect peripheral blood progenitor cells (PBPC) and red blood cell units for use in the recipient after allogeneic PBPC transplantation. Haematologica 86: 12091218

82. Schapira L, Antin JH, Ransil BJ, Antman KH, Eder JP, McGarigle CJ, Goldberg MA (1990) Serum erythropoietin levels in patients receiving intensive chemotherapy and radiotherapy. Blood 76: 2354-2359

83. Steegmann JL, Lopez J, Otero MJ, Lamana ML, de la Camara R, Berberana M, Diaz A, Fernandez-Ranada JM (1992) Erythropoietin treatment in allogeneic BMT accelerates erythroid reconstitution: results of a prospective controlled randomized trial. Bone Marrow Transplant 10: 541-546

84. Taniguchi S, Yamasaki K, Shibuya T, Asayama R, Harada M, Niho Y (1993) Recombinant human erythropoietin for long-term persistent anemia after major ABO-incompatible bone marrow transplantation [letter]. Bone Marrow Transplant 12: 423

85. Ustun C, Celebi H, Arat M, Ozcan M, Dilek I, Gurman G, Demirer T, Ilhan O, Keskin R, Koc H (1999) Treatment of aregeneratoric anemia following an ABOincompatible allogeneic peripheral blood stem cell transplantation: a case report. Ther Apher 3: 275-277

86. van den Bent MJ, Bos GM, Sillevis Smitt PA, Cornelissen JJ (1999) Erythropoietin induced visual hallucinations after bone marrow transplantation [letter]. J Neurol 246: 614-616 
87. Vannucchi AM, Bosi A, Grossi A, Guidi S, Saccardi R, Lombardini L, Rossi Ferrini P (1992) Stimulation of erythroid engraftment by recombinant human erythropoietin in ABO-compatible, HLA-identical, allogeneic bone marrow transplant patients. Leukemia 6: 215-219

88. Vannucchi AM, Bosi A, Grossi A, Guidi S, Saccardi R, Rossi-Ferrini P (1994a) Down-modulation of serum erythropoietin levels following cyclosporin A infusion [letter]. Bone Marrow Transplant 13: 497-498

89. Vannucchi AM, Bosi A, Ieri A, Guidi S, Saccardi R, Lombardini L, Linari S, Laszlo D, Longo G, Rossi-Ferrini P (1996) Combination therapy with G-CSF and erythropoietin after autologous bone marrow transplantation for lymphoid malignancies: a randomized trial. Bone Marrow Transplant 17: 527-531

90. Vannucchi AM, Bosi A, Linari S, Guidi S, Longo G, Lombardini L, Mariani MP, Saccardi R, Laszlo D, Rossi FP (1997) High doses of recombinant human erythropoietin fail to accelerate platelet reconstitution in allogeneic bone marrow transplantation. Results of a pilot study. Haematologica 82: 53-56

91. Vannucchi AM, Grossi A, Bosi A, Rafanelli D, Guidi S, Saccardi R, Alterini R, Ferrini PR (1991) Impaired erythropoietin production in mice treated with cyclosporin A. Blood 78: 1615-1618

92. Vannucchi AM, Grossi A, Bosi A, Rafanelli D, Statello M, Guidi S, Rossi-Ferrini P (1993) Effects of cyclosporin A on erythropoietin production by the human Hep3B hepatoma cell line. Blood 82: 978-984

93. Vannucchi AM, Grossi A, Rafanelli D, Statello M, Cinotti S, Rossi-Ferrini P (1994b) Inhibition of erythropoietin production in vitro by human interferon gamma. Br J Haematol 87: 18-23

94. Waller CF, von Lintig F, Daskalakis A, Musahl V, Lange W (1999) Mobilization of peripheral blood progenitor cells in patients with breast cancer: a prospective randomized trial comparing rhG-CSF with the combination of rhG-CSF plus rhEpo after VIP-E chemotherapy. Bone Marrow Transplant 24: 19-24

95. York A, Clift RA, Sanders JE, Buckner CD (1992) Recombinant human erythropoietin (rh-Epo) administration to normal marrow donors. Bone Marrow Transplant 10: 415-417

96. Youssoufian H, Longmore G, Neumann D, Yoshimura A, Lodish HF (1993) Structure, function, and activation of the erythropoietin receptor. Blood 81: 2223-2236

Correspondence: Yves Beguin, MD, University of Liège, Department of Hematology, CHU Sart-Tilman, 4000 Liège, Belgium, E-mail: yves.beguin@chu.ulg.ac.be 